\title{
First Trimester Ultrasound Screening: An Update
}

\author{
1,2JD Sonek, ${ }^{1} \mathrm{M}$ Glover, ${ }^{1} \mathrm{M}$ Zhou, ${ }^{3} \mathrm{KH}$ Nicolaides \\ ${ }^{1}$ Wright State University, Dayton $\mathrm{OH}, \mathrm{USA}$ \\ ${ }^{2}$ Fetal Medicine Foundation/USA, Dayton OH, USA \\ ${ }^{3}$ King's College School of Medicine and Dentistry, Harris Birthright Center, London, UK
}

Correspondence: JD Sonek, Wright State University, Dayton OH, USA, e-mail: jdsonek@mvh.org

\begin{abstract}
For many years, the main use of ultrasound in the first trimester of pregnancy was to confirm viability and to establish gestational age. Indeed, the crown-rump length measurement in the first trimester remains the most accurate method to estimate the gestational age even today. However, improvements in ultrasound equipment and improvement in our understanding of normal and abnormal fetal development allows us now to perform a much more complete first trimester fetal evaluation. This pertains not only to the diagnosis of fetal anomalies but also to screening for fetal defects. The combination of the nuchal translucency measurement and maternal serum biochemistries (free $\beta$-hCG and PAPP-A) has been shown to be an extremely efficient way to screen for fetal aneuploidy. The addition of other first trimester markers such as the nasal bone evaluation, frontomaxillary facial angle measurement, and Doppler evaluation of blood flow across the tricuspid valve and through the ductus venosus improves the screening performance even further by increasing the detection rates and decreasing the false positive rates. Several of the first trimester markers also are useful in screening for cardiac defects. Furthermore, significant nuchal translucency thickening has been associated with a variety of genetic and nongenetic syndromes. A recently described first trimester marker called the intracerebral translucency appears to hold great promise in screening for open spine defects. Finally, it appears that a first trimester evaluation (uterine artery Doppler and the measurement of certain biochemical markers in the maternal serum) significantly improves the assessment of the risk of preeclampsia.
\end{abstract}

Keywords: First trimester screening, nuchal translucency, nasal bone, frontomaxillary angle, ductus venosus, tricuspid valve, intracranial translucency, uterine artery.

\section{INTRODUCTION}

The utility of the first trimester ultrasound examination of the gravid uterus and its contents continues to expand. The first trimester evaluation of the fetus, maternal pelvic vasculature, and maternal serum in conjunction with maternal history and physical examination may be used to establish the risk of fetal aneuploidy and some complications that do not become clinically evident until later in pregnancy. This paper reviews the current information regarding the benefits and limitations of this approach.

Gray scale examination of the fetal head and neck yields a great amount of information regarding the risk of trisomy 21 and other aneuploidies. Many of the ultrasound markers that are used in the first trimester to establish the risk of trisomy 21 have their equivalents in the postnatal phenotype. In 1866, Langdon Down ${ }^{1}$ described individuals with the syndrome that later came to bear his name as "having skin that appears to be too large for their bodies" [hence the increased nuchal translucency (NT) thickness], ${ }^{2}$ having a "small nose" [hence the nasal bone (NB) absence or hypoplasia], ${ }^{3}$ and having a "flat face" [hence the shallow frontomaxillary facial (FMF) angle]. ${ }^{4}$
Gray scale examination of the fetal heart in the first trimester may yield evidence of a cardiac defect, which is the most common structural anomaly seen in individuals with trisomy $21 .{ }^{5}$ However, even in the absence of an overt structural defect, the function of the heart may be altered. There is ample evidence that the microscopic and ultrastructural anatomy of the myocardium and valve leaflets is abnormal. ${ }^{6-8}$ These findings were exploited to develop a second type of ultrasound marker: Doppler evaluations of the cardiovascular system. The two tests of this type that are proving to be especially useful are the evaluation of blood flow across the tricuspid valve (TCV) ${ }^{9-11}$ and through the ductus venosus (DV). ${ }^{12-19}$ The third marker that falls into the general category of cardiovascular markers is evaluation of the fetal heart rate (FHR). ${ }^{2,20}$ This marker is only marginally helpful in screening for trisomy 21 but, as will be discussed later, may be helpful in screening for other types of aneuploidy.

Pregnancy is associated with an alteration of levels of a number of substances that circulate in the maternal blood. Through empirical observations and studies, it has been noted that some of these are present in concentrations that are different in aneuploid pregnancies as compared to those 
that are chromosomally normal. The two substances that have been shown to be especially useful in screening for trisomy 21 are free beta-human chorionic gonadotropin (free $\beta$-hCG) and pregnancy associated plasma protein-A (PAPPA). ${ }^{21}$ It should be stressed that it is the free $\beta$-hCG rather than other forms of hCG that has been tested most rigorously and that appear to perform the best. ${ }^{22}$

First trimester screening has been shown to be useful not only for trisomy 21 but for other types of aneuploidy (trisomies 18 and 13, monosomy X, other aneuploidies involving the sex chromosomes, and triploidy). ${ }^{2,3,22-24}$ Some of these tend to have nuchal translucencies that are even thicker than trisomy 21 and are more likely to have major or minor structural defects. As a result the detection rates are in some cases even higher than for trisomy $21 .^{2,22}$

A first trimester marker called the intracranial translucency (IT) has been recently described. ${ }^{25}$ This marker appears to be useful in screening for open neural tube defects. It remains to be proven whether this marker is as powerful as the Chiari type II malformation and bifrontal scalloping in the second trimester.

First trimester Doppler evaluation of the maternal uterine arteries and measurement of levels of certain substances in the maternal serum along with maternal blood pressure measurement, have been shown to be useful in estimating the risk of preeclampsia. ${ }^{26-29}$ This is especially true for early and severe preeclampsia, which is frequently associated with fetal growth restriction. The utility of this approach is limited by the fact that there is no proven method for the prevention of either one of these conditions. However, identification of the truly high risk patients early in pregnancy may lead to methods that improve pregnancy outcome in the future.

The Fetal Medicine Foundation (FMF) played an active role in the development and implementation of the above mentioned markers. They are included in the current FMF algorithm for the first trimester pregnancy evaluation.

\section{An Argument for Screening in the First Trimester}

There are a number of benefits that a pregnancy evaluation in the first trimester offers. Firstly, first trimester screening that combines ultrasound and maternal serum markers (PAPP-A and free $\beta$-hCG) has the highest detection rates for fetal aneuploidy currently available. ${ }^{30}$ Secondly, NT measurements are helpful in establishing the risk of a number of fetal disorders other than aneuploidy. ${ }^{31-79}$ Thirdly, a fairly complete fetal anatomic evaluation may be performed even in the first trimester. ${ }^{80-91}$ Therefore, the patient is provided with a great amount of information early in pregnancy. If a fetal problem is detected, this approach preserves maximum privacy and autonomy as well as safety with regards to her reproductive choices. Lastly, first trimester ultrasound evaluation includes the (CRL) measurement which is the most accurate method for estimating the gestational age. ${ }^{92}$ Arguably, an accurate gestational age is one of the most important pieces of information in the management of both at-risk and normal pregnancies.

The first trimester ultrasound has even more benefits in the case of multiple gestations. Firstly, the first trimester is the optimal time to establish the chorionicity and amniocity in a multiple gestation. ${ }^{93-95}$ A distinct thickening of the dividing membrane ("lambda" or "twin peak" sign) as it approaches the placental surface indicates that the gestation is dichorionic (DC). If the membrane is thin throughout its entire length including the point, where it meets the placental surface ("T" sign), the diagnosis of a monochorinic/ diamniotic (MC/DC) gestation may be confidently made. The knowledge of chorionicity is very useful in the overall management of the pregnancy; MC/DC gestations are at a significantly high risk for a variety of adverse perinatal outcomes than DC gestations. Furthermore, establishing the chorionicity helps to select the appropriate algorithm to calculate the aneuploidy risk. ${ }^{96-98}$ Unlike maternal serum biochemistries, the use of ultrasound markers in multiple gestations allows for this risk to be assigned to each fetus individually, rather than establishing a risk for the pregnancy overall. Maternal serum markers in higher order multiple gestations (triplets and greater) are unreliable and first trimester ultrasound screening is the best option.

In monochorionic/diamniotic gestations, the risk of developing twin-to-twin transfusion syndrome (TTTS) later in pregnancy may be estimated by measuring the NT (the likelihood of TTTS increases with increasing difference in the NT measurements between the two fetuses), ${ }^{99}$ and by evaluating the ductus venosus with Doppler (presence of reversed a-wave increases the risk of TTTS). ${ }^{100}$

\section{An Argument for Confining the First Trimester Ultrasound Exam to 11-13 + 6 weeks' Gestation}

The inclusion of an ultrasound examination in first trimester screening results in benefits that extend well beyond just screening for aneuploidy. Imposing the lower limit of 11 weeks' gestation for first trimester screening assures that the benefits of the ultrasound examination are maximized.

Firstly, an anatomic survey of the fetus performed after 11 weeks' gestation is much more likely to produce usable information than an examination done prior to this gestational age. This applies not only to identification of anomalies but also to simply being able to visualize normal structures. ${ }^{101}$ There are some transient structural alterations that are normal in the embryonic and early fetal period that 
may make the diagnosis of certain anomalies more difficult. One is the presence of a physiologic extra-abdominal herniation of the bowel that makes the diagnosis of an omphalocele difficult prior to 11 weeks' gestation. ${ }^{102-104}$ The absence of ossification of the cranial vault prior to 11 weeks' gestation reduces the accuracy of the diagnosis of the first trimester exencephaly/anencephaly sequence. ${ }^{105}$ Finally, aside from the NT measurement, the effectiveness of first trimester markers prior to 11 weeks gestation is unknown but is likely to be reduced (e.g. the nasal bone is not normally ossified prior to 11 weeks' gestation, ${ }^{106}$ almost $50 \%$ of normal fetuses have incompetent tricuspid valves at 10 weeks' gestation). ${ }^{107}$

There are several reasons for not extending the NT-based screening beyond $13+6$ weeks' gestation. Firstly, the effectiveness of NT measurement as a marker of aneuploidy diminishes in effectiveness with advancing gestational age. ${ }^{108}$ Secondly, the position of the fetus within the uterus tends to be such that the nuchal translucency measurement is more difficult to acquire. ${ }^{109,110}$ Thirdly, the estimation of gestational age based on a CRL measurement is no longer accurate. Lastly, the patient now enters the second trimester thus reducing the benefits of early diagnosis and treatment.

\section{ELEMENTS OF FIRST TRIMESTER FETAL SCREENING}

\section{General Principles of Screening}

The development of a credible screening protocol has a number of essential components. Firstly, a marker (ultrasound or maternal serum) needs to be identified. A marker for aneuploidy is defined as a finding that has a different prevalence in the euploid and aneuploid populations. A likelihood ratio that is associated with the marker is calculated by dividing the two prevalences. The strength of the marker increases as this difference increases. It needs to be determined whether the likelihood ratio is influenced by maternal or fetal factors. If more than one marker is used, it needs to be established whether or not they perform independently of each other. If there is weak association between the two markers, this usually may be compensated for mathematically. If the association is strong, it may be best not to use them together. The technique, which is used to examine a marker, must be standardized so it is reproducible and may be implemented in more than one center.

The implementation of a credible screening protocol also has a number of essential components. Above all, only those operators that have the appropriate background and training should be involved in the performance of screening. It is equally important to establish a quality assurance system that reviews the performance of the screening on an ongoing basis.

\section{General Principles of the Use of Ultrasound and Biochemical Markers}

Each of the markers that are included in the FMF algorithm has its own likelihood ratio associated with it, which is appropriately adjusted for maternal and fetal factors. Some of the markers are measured as a quantitative parameter (NT, FMF angle, fetal heart rate, maternal serum biochemistries). They are used as continuous variables and each measurement has its own likelihood ratio associated with it. While using these types of variables, the detection rates and false positive rates may be changed by changing the cut-off value that is used to separate the "high-risk" group from the "low-risk" group. The remaining markers (NB, TCV, DV, "soft" markers, fetal anomalies) are evaluated qualitatively. They are assigned a likelihood ratio, which depends on whether they are present or absent. The detection rates and the false positive rates of these markers cannot be mathematically changed since their prevalences in the normal and abnormal populations are fixed.

The manner in which the majority of markers for fetal aneuploidy are used is to adjust the patient's a priori (background) risk. The only exception is certain fetal anomalies (see below). They have such a high association with aneuploidy that the a priori risk is irrelevant and the risk that they confer is fixed.

The a priori risk is usually based on the maternal age. However, other less common factors such as a prior offspring with aneuploidy or a balanced parental translocation also increase the a priori risk. ${ }^{111,112}$

\section{Crown-rump Length}

It is important to obtain an accurate crown-rump length (CRL) as the calculation of fetal risk must be based on the correct gestational age. ${ }^{92}$ A midline longitudinal view of the fetus is obtained and the image is magnified so that the fetus fills most of the image. The fetus is measured from the top of the head to the rump. The measurement should be done with the fetus in a neutral position, i.e. not hyperflexed or extended.

\section{Nuchal Translucency}

The NT is formed by a layer of fluid beneath the nuchal skin extending for a variable distance over the head and neck. ${ }^{113}$ This layer of fluid is present in all fetuses between 11 and $13+6$ weeks of gestation. It has been shown that as 
the amount of this fluid increases, there is an increasing chance of the fetus being affected by some type of a disorder. However, as is the case with every true marker, even a very significant increase in NT thickness does not make the diagnosis of a fetal problem. This can be determined only by the appropriate diagnostic test such as chorionic villus sampling or amniocentesis.

\section{Possible Mechanisms for Thickened Nuchal Translucency}

There are a number of mechanisms that have been proposed for the nuchal thickening: structural cardiovascular abnormalities and/or abnormalities of myocardial performance, ${ }^{6,114-117}$ abnormalities of connective tissue composition, ${ }^{7,8,118-120}$ abnormalities ordelay inlymphatic system formation, ${ }^{66,67,121,122}$ increase in intrathoracic pressure, ${ }^{48,54-61}$ decrease in fetal movement, ${ }^{50,70-72}$ fetal hypoproteinemia, ${ }^{69,123}$ fetal anemia, ${ }^{73-76}$ and fetal infection. ${ }^{77-79,124}$ It is likely that under different clinical circumstances, different mechanisms are in effect. It is also likely that in many cases, especially in fetuses with chromosomal defects, the thickened NT is caused by more than one mechanism.

\section{Nuchal Translucency Measurement}

The relative amount of nuchal fluid may be estimated by measuring the thickness of the hypoechoic layer that it forms with the fetus in a longitudinal view. In order for this marker to be reproducible and usable in multiple centers, the method of measurement has been standardized by the FMF (Fig. 1). The magnification is such that the fetal head and the upper thorax occupy the majority of the image. This is done so the accuracy of the NT measurement is $0.1 \mathrm{~mm} .{ }^{125}$ A midline section is obtained with the fetus either facing towards or away from the transducer. There are a number of anatomic

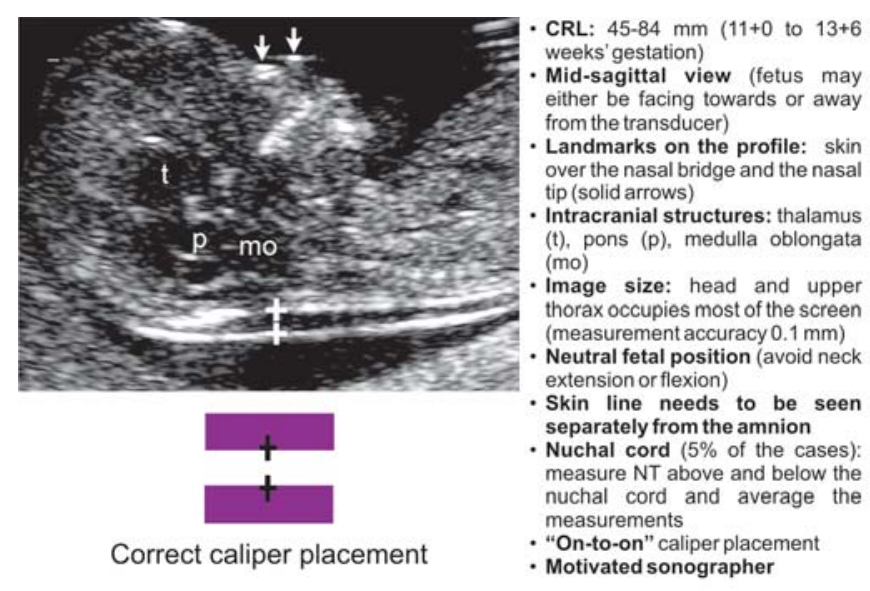

Fig. 1: Nuchal translucency measurement landmarks that help to establish that the ultrasound plane is in the midline: delineation of the fetal profile with echogenic lines representing the skin over the nasal bridge and nasal tip being visible in the same view (only if the fetus is facing the transducer) and the intracranial hypoechoic regions of the thalamus, the pons and the medulla oblongata (if the fetus is either facing towards or away from the transducer). The fetal neck should be neither extended or hyperflexed. Extension artificially increases the nuchal translucency measurement and hyperflexion decreases it. ${ }^{126}$ Cross-shaped calipers should be used. This allows for optimal standardization of the caliper placement: the inner aspect of the caliper cross hatch should be flush with the inner aspect of the echodense lines bracketing the nuchal fluid. The ultrasound settings should be adjusted so these lines are as thin and sharply delineated as possible. The NT may be best visualized and the echogenic lines are sharpest if the face of the transducer is approximately parallel to the longitudinal axis of the fetus and the nuchal skin is insonated at $90^{\circ}$. The nuchal translucency must be clearly differentiated from the amniotic membrane, which has a similar ultrasound appearance to the skin line. The measurement, which is used for the risk calculation should be taken at the thickest part of the NT. Optimally, the measurement should be performed on at least three separate images and the largest measurement that meets the criteria should be used.

In approximately $5 \%$ of the cases, a nuchal cord is identified. ${ }^{127}$ This is usually first suspected when a segment of the nuchal translucency cannot be clearly visualized. Often, faint echodense lines are seen in this region, which represent a cross-section of the tortuous umbilical vessels. The presence of a nuchal cord is best confirmed with color Doppler. It is felt that a nuchal cord causes redistribution of the nuchal fluid. An acceptable method to compensate for this redistribution is to measure the NT above and below the nuchal cord. The risk assessment is based on the average of the two measurements.

For a given measurement, the appearance of the NT does not change the risk of a fetal abnormality being present. Therefore, the risk assessment should be based on the NT measurement alone. On close inspection, septations may be seen in essentially all thickened nuchal translucencies. ${ }^{128}$ Therefore, attempting to differentiate between simple nuchal translucency and a "cystic hygroma" is not useful. Assigning different risks based on the appearance of the NT was proposed as a part of the FASTER study. ${ }^{129}$ The statistical analysis used in this article was questioned by some. ${ }^{130}$ Additionally, subsequent analysis of the same data by the FASTER group did suggest that NT size rather than appearance is most important. ${ }^{131}$ 


\section{Nuchal Translucency and Fetal Aneuploidy}

The prevalence of chromosomal defects increases with increasing NT thickness. ${ }^{132,133}$ The relation between fetal NT and chromosomal defects was initially derived from a multicenter screening study involving 96,127 singleton pregnancies. ${ }^{132}$ The distribution of these measurements has slightly changed since that time. This is due to minor changes in the technique used to measure the NT and due to changes in ultrasound equipment. The distribution of normal measurements that is currently used for risk estimation is based on 37,078 fetuses examined in a standardized fashion at the Fetal Medicine Center in London between 1999 and $2005{ }^{108}$

The mathematical description of the NT measurement distribution and the manner in which the likelihood ratios are generated have evolved over the past 15 years. Recently, a mixture model of the NT measurement distributions has been introduced. ${ }^{108}$ This model is based on the observation that the NT measurement distributions in both the euploid and the aneuploid fetuses follow two distinct patterns. In a certain proportion of the fetuses, the nuchal translucency measurements increase between 11 and $13+6$ weeks' gestation, whereas in another proportion, the NT measurements are independent of the gestational age and remain constant over this time period. The percentage of populations that fit into these two categories is different depending on the chromosomal complement.

If done correctly, NT measurement is arguably the most robust single marker for fetal aneuploidy. ${ }^{30}$ Therefore, NT measurement should be a part of any screening protocol that includes first trimester ultrasound examination. Using just the combination of maternal age and NT measurement, the detection rates for a $5 \%$ false positive rate are about $75 \%$ for trisomies 21,18 and 13 , and are $90 \%$ and $60 \%$ for monosomy $\mathrm{X}$ and triploidy respectively. ${ }^{132,134,135}$

Maternal serum analytes that have been shown to be most effective in first trimester screening for aneuploidy are free $\beta$-hCG and PAPP-A. Nuchal translucency measurements and the serum analytes levels are independent of each other. Therefore, the two may be used together along with maternal age-related risk (combined first trimester screen) without the need for additional mathematical manipulation. ${ }^{21,136-140}$ The combined screening improves the detection rate for trisomies 21, 18 and 13, monosomy X, and triploidy to $90 \%$ or more for a $5 \%$ false positive rate. ${ }^{2,141,142}$

\section{Nasal Bone}

The logic behind using the prenatal nasal bone evaluation in screening for trisomy 21 is based on the characteristic facial features found in individuals with Down syndrome and anthropometric, radiological, and histological studies. ${ }^{143-147}$ All of these studies demonstrate a significant difference in either the size of the nasal bone or in the degree of ossification between euploid individuals and those with trisomy $21 .{ }^{148}$

Since the confirmation that this phenomenon appears to be present on prenatal ultrasound, ${ }^{149}$ a number of studies have been published indicating that absence of the nasal bone is highly associated with trisomy 21 in both the first and the second trimesters.

Recently, the routine evaluation of the nasal bone (absence or hypoplasia) in postmortem fetal examinations has been proposed as a marker for developmental disturbances in the frontonasal region. ${ }^{150}$

\section{Mechanism for the Nasal Bone Absence in Trisomy 21}

The exact mechanism leading to the nasal bone abnormalities seen in trisomy 21 is unknown. However, it is likely that the changes in connective tissue known to exist in trisomy 21 are at least in part responsible. ${ }^{118-120,146,147}$

\section{Ultrasound Evaluation of the Fetal Nasal Bone}

In the first trimester, the nasal bridge is evaluated only for the presence or absence of the nasal bone. ${ }^{148,151-156}$ Unlike in the second trimester, measuring the nasal bone does not appear to improve the screening performance of the test. ${ }^{148,157}$

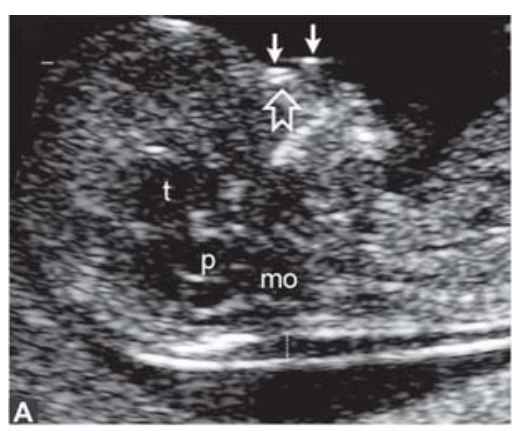
- CRL: $45-84 \mathrm{~mm}(11+0$ to $13+6$
weeks' gestation)
- Mid-sagittal view (fetus must be
facing towards the transducer)
- Image size: head and upper
thorax occupies most of the screen
- The face of the transducer is
parallel to the long axis of the nasal
bone and the skin over the nasal
bridge
- Fetal profile must include an
echogenic line representing the
skin over nasal bridge and an
echogenic line representing the
skin over the nasal tip (solid
arrows)
- Intracranial structures: hypo-
echoic areas representing the
region of the thalamus ( $t$ ), pons ( $p$ ),
and the medulla oblongata (mo)
- If the nasal bone is present, a line
(notched arrow) that is more
echogenic than the skin is seen
within the nasal bridge. This line is
approximately parallel to the skin
over the nasal bridge; the two lines
forma so-called "equal sign".

Figs 2A and B: Nasal bone assessment (A) nasal bone present, (B) nasal bone absent 
The protocol for an ultrasound evaluation of the nasal bone is shown in Figures 2A and B. The fetal profile needs to be insonated in the midline plane. This is determined by visualizing the following fetal structures: the hypoechoic region of the thalamus, pons, and medulla oblongata, the echogenic line over the nasal bridge representing the skin, and an echogenic line that is located anteriorly and slightly superiorly to the nasal bridge, which represents the skin over the nasal tip. If the nasal bone is present, an echogenic line is also seen within the substance of the nasal bridge. This line is approximately parallel to the line representing the nasal bridge skin. These two lines form a so-called "equal sign". The echogenicity of the nasal bone needs to be greater than that of the skin in order for the nasal bone to be identified as present. The reason for this requirement is that even if the nasal bone is not ossified (i.e. sonographically absent), a very faint echodense line may be seen within the nasal bridge.

In order to be able to visualize the required anatomic landmarks and to see the nasal bone as a separate structure from the nasal skin, significant magnification is required: the fetal head an upper thorax should occupy the majority of the image.

The angle of insonation is extremely important in the evaluation of the nasal bone. The face of the transducer should be parallel to the longitudinal axis of the nasal bridge and the nasal bone $\left(90^{\circ}\right.$ angle of insonation). The nasal bone may become sonographically invisible, if there is a significant deviation from this angle. This is due to the fact that the NB is an extremely thin structure. The lateral resolution of the ultrasound equipment is insufficient to visualize the NB if it is viewed "on-end" (close to $0^{\circ}$ angle of insonation). Finally, the nasal bone evaluation may be done only with the fetus facing the transducer.

Three-dimensional ultrasound does not appear to significantly improve the success of examination of the nasal bone. ${ }^{158}$ However, one advantage that it holds over the 2D examination is that it can reliably identify unilateral absence of the nasal bone. ${ }^{158}$ The exact likelihood ratio associated with this finding has not been established. However, since it has been seen in association with trisomy 21, unilateral nasal bone absence has been for now assigned the same significance as bilateral nasal bone absence.

\section{Nasal Bone and Fetal Aneuploidy}

The likelihood ratio associated with the NB findings needs to be adjusted for gestational age. ${ }^{159}$ Overall, the prevalence of an identifiable NB increases with increasing gestational age. If the NB is not visualized at 11-12 weeks' gestation, it is recommended to repeat the ultrasound examination one week later and use the results of the second examination for the risk calculation. This approach decreases the false positive rate.

The prevalence of NB presence and absence is also influenced by ethnicity. ${ }^{159}$ The prevalence of NB absence is the lowest in Caucasians and it is most common in persons of African origin. The prevalence in Asians falls between the two. This difference in prevalence applies to both euploid fetuses and fetuses with trisomy 21.

There is a relationship between the NT measurement and the prevalence of NB absence. However, this does not appear to be significant until the NT measurement exceeds the 99th percentile $(3.5 \mathrm{~mm}) .{ }^{159}$ Therefore, most of the time the likelihood ratio based on the nasal bone evaluation does not have to be adjusted for the NT measurement.

A review of several major studies demonstrates that based on examinations of approximately 49,000 fetuses the prevalence of NB absence in euploid fetuses in the first trimester is $1-3 \%$ and is $65 \%$ in fetuses with trisomy $21 .{ }^{148}$ An increased prevalence of NB absence has also been found in trisomy 18 (55\%), trisomy 13 (34\%), monosomy X (11\%) but not in triploidy. ${ }^{159}$

The presence or absence of NB is independent of the maternal serum markers (free $\beta$-hCG and PAPP-A). ${ }^{3}$, 151,160,161 Therefore, this evaluation may be added to the first trimester combined screen. A study involving 19,614 fetuses demonstrates that with the addition of NB evaluation to the combined screen, for a false positive rate of $3 \%$ the detection rate of trisomy 21 was $92 \%$ and the detection rate for trisomies 18,13 , and for monosomy $\mathrm{X}$ was $100 \%{ }^{3}$

\section{Frontomaxillary Facial Angle}

Flat facies is recognized as a common dysmorphic features in individuals with Down syndrome. This may be subjectively assessed even on prenatal ultrasound by examining the fetal profile. However, in order for this facial feature to be exploited for screening purposes, a method had to be found to evaluate it using a standardized measurement. The frontomaxillary facial (FMF) angle measurement is an objective way to estimate mid-face hypoplasia; the deeper the location of the front edge of the maxilla is with respect to the forehead, the shallower the FMF angle. ${ }^{162}$ The reason for the mid-face hypoplasia in trisomy 21 also appears to be the presence of abnormal connective tissue. Theoretically, abnormal bone modeling due to hypotonia of the tongue may also be a contributing factor.

\section{Frontomaxillary Facial Angle Measurement}

The image requirements for the FMF angle measurement (Fig. 3) are very similar to those for the NB evaluation. The 


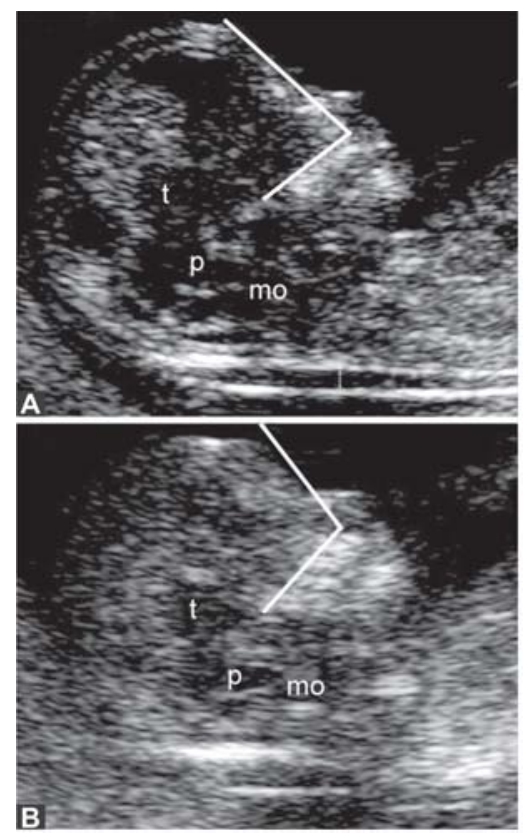

CRL: $45-84 \mathrm{~mm}(11+0$ to $13+6$ weeks' gestation)

Mid-sagittal view (fetus must be facing towards the transducer)

Image size: head and upper thorax occupies most of the screen

Face of the transducer is approximately parallel to the long axis of the nasal bone

Fetal profile must include an echogenic line representing the skin over nasal bridge and an in front of it an echogenic line representing the skin over the nasal tip

- Intracranial structures: hypoechoic areas representing the region of the thalamus $(t)$, pons $(p)$, and the medulla oblongata $(\mathrm{mo})$

Space between the upper palate and the nose should be devoid of an echogenic structure representing the zygomatic process

FMF angle: first ray is drawn along the upper edge of the hard palate, apex of the angle is at the anterior edge of the maxilla, second ray runs upwards from the apex resting on the echogenic line beneath the skin (the noncalcified beneath the skin (the noncalcified
metopic suture)

Figs $3 \mathrm{~A}$ and B: Frontomaxillary facial angle measurement. (A) an acute angle in an euploid fetus, (B) an obtuse angle in a fetus with trisomy 21

head and the upper thorax should fill the majority of the image and the fetus needs to be facing the transducer. The greatest of care must be taken to obtain a precise midline view as only a small deviation from the midline significantly affects the measurement. ${ }^{163}$ The landmarks that are used to determine this are also similar to those, which are used for the NB evaluation: echogenic skin over the nasal bridge and nasal tip seen in the same view on the surface of the profile and the intracranial hypoechoic regions of the thalamus, pons, and the medulla oblongata. ${ }^{163}$ Additionally, in the precise midline view, the area between the upper edge of the hard palate and the nasal bone is relatively echo free. As the plane of insonation deviates slightly from the midline, an echogenic structure comes into view. This represents the zygomatic process of the maxilla, a finding that should be absent in the correct view. The use of 3D ultrasound may be helpful to establish the correct view. ${ }^{163}$

। The angle of insonation is also similar to the one required for the nasal bone evaluation: the face of the transducer should be roughly parallel to the long axis of the NB and the skin over the nasal bridge. The hard palate, which is composed of the maxilla and the vomer bones, is seen as a roughly trapezoid echogenic structure with the posterior portion being slightly thicker than the front one.

In order to measure the frontomaxillary angle, the following lines are generated. The first one runs along the upper edge of the hard palate. The vertex of the angle is at the anterior-most portion of the maxilla. The second line of the angle runs upwards from the vertex towards the forehead.
It is positioned so its inner edge rests upon the metopic suture, which lies a short distance beneath the skin. In the first trimester, the metopic suture is not yet ossified. Therefore, it is seen as a line of similar echogenicity as the skin.

The deep position of the front edge of the maxilla in fetuses with trisomy 21 may be due to maxillary hypoplasia, dorsal displacement of the maxilla, or a combination of the two. Figures $3 \mathrm{~A}$ and $\mathrm{B}$ illustrates the difference between FMF measurements in a fetus with trisomy 21 and in a euploid fetus.

In the first trimester, the division between the vomer bones and the maxilla is usually difficult to see. However, towards the end of the first trimester, this division may become evident as an oblique hypoechoic line running from the upper edge of the hard palate anteriorly to the lower edge of the hard palate posteriorly. ${ }^{164}$ This line should not be used to form the lower ray of the FMF angle.

\section{Frontomaxillary Angle and Fetal Aneuploidy}

The normal ranges of the frontomaxillary angle measurements decrease with advancing gestational age. ${ }^{165}$ They are independent of NT measurements, presence or absence of the nasal bone, and maternal serum biochemistries. ${ }^{4,} 162$

Shallow FMF angles are seen not only in trisomy 21 but also in trisomies 18 and 13. Fetuses with trisomies 21, 18, and 13 have FMF angle measurements that are above the 95th percentile in $45 \%, 58 \%$, and $48 \%$ cases respectively. ${ }^{4,166,167}$ In a study, which included 782 euploid fetuses and 108 fetuses with trisomy 21, a 92\% detection rate for a $3 \%$ false positive rate was achieved by adding FMF angle measurement to the combined screen. ${ }^{4}$

\section{Doppler Evaluations of Fetal Blood Flow as Markers for Aneuploidy}

The fetal cardiovascular system has a number of structural and functional features that differentiate it from the cardiovascular system ex utero. The arrangement of the myocytes within the fetal heart is less well-organized and there are fewer sarcomeres per unit mass. ${ }^{6}$ The fetal myocardium has lower compliance resulting in a higher intraventricular pressure at any cardiac volume. Early in pregnancy, the placental vascular resistance is relatively high placing additional strain on the heart. As a consequence, the fetal heart functions at the upper limits of the FrankStarling curve. In the first trimester, abnormalities of cardiac structure and/or performance may lead to detectable changes in blood flow through certain structures. The two structures that have been investigated the most and hold promise in screening for aneuploidy are the tricuspid valve (TCV) ${ }^{168}$ 


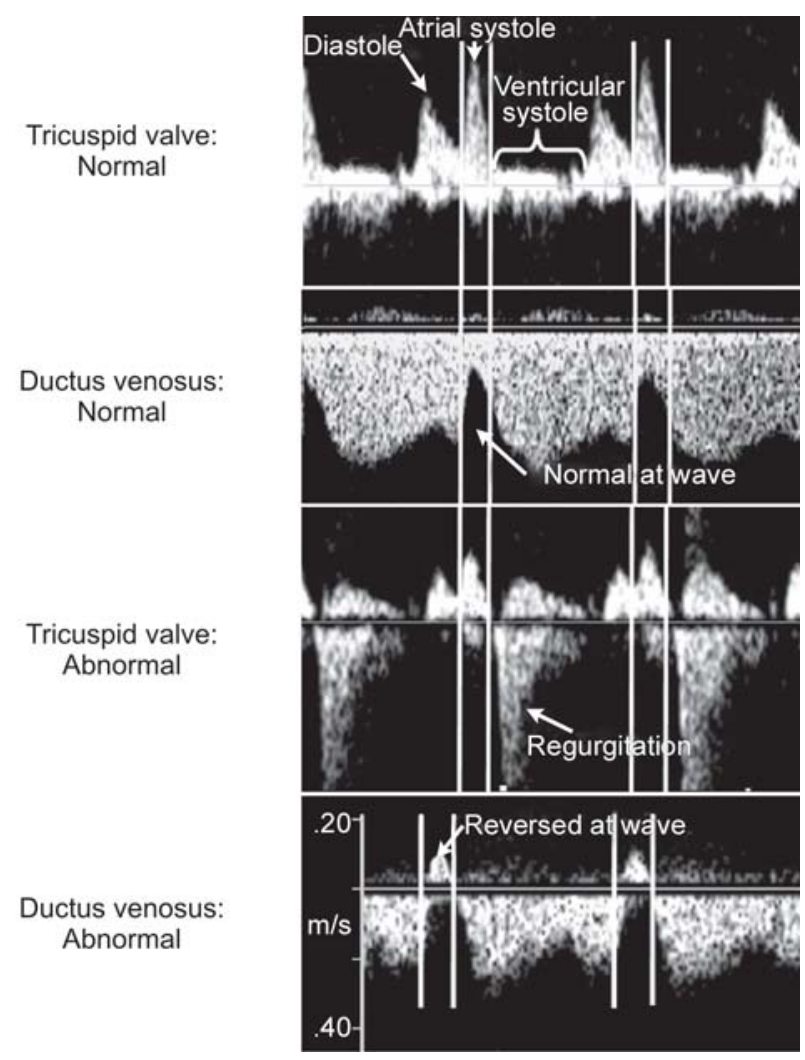

Fig. 4: Temporal relationship of pulsed Doppler waveforms across the TCV and the DV: normal and abnormal

and the ductus venosus (DV). ${ }^{169}$ The DV is strictly a fetal structure that carries $50 \%$ of the oxygenated blood from the umbilical vein and empties into the inferior vena cava at a point that is very close to the right atrium. Its proximity to the right side of the heart makes it susceptible to changes in the cardiac function. ${ }^{170-182}$ Tricuspid valve flow is considered abnormal in the presence of regurgitation and the DV venous flow is considered abnormal if the a-wave is reversed (see below). The temporal relationship between the Doppler flow patterns across the TCV and DV are demonstrated in Figure 4.

\section{Tricuspid Valve Regurgitation}

The exact reason for the increased prevalence of tricuspid valve regurgitation in fetuses with trisomy 21 is not completely clear. However, it is likely that it is related to the structural and ultrastructural changes in the heart that are known to be associated with trisomy 21: decreased number of myocytes, abnormal orientation of myocytes and myofibrils, and abnormal connective tissue. ${ }^{6,8,118-120}$ It may be that these changes result in a relative dilatation of the right ventricle. It is also recognized that dilatation of the right ventricle may lead to tricuspid regurgitation by dilating the tricuspid valve annulus. Finally, the connective tissue abnormalities that affect the myocardium are also present in the valve itself. ${ }^{8}$ It may be that both of these mechanisms are involved in causing TCV incompetence and regurgitation.

\section{Pulsed Doppler Evaluation of Blood Flow across the Tricuspid Valve}

The protocol for TCV evaluation using pulsed Doppler is shown in Figures 5A and B. A magnified transverse section of the fetal thorax containing a four chamber view is obtained. The angle of insonation is important. The heart view should be apical so that the angle of insonation with respect to the ventricular septum is less than $30^{\circ}$. The Doppler gate is placed across the TCV. The gate should be relatively large (2-3 mm) to make certain that it covers both sides of the valve. It should be kept in mind that not all of the leaflets of the TCV are necessarily incompetent. Therefore, at least three Doppler evaluations should be obtained. It is also helpful to interrogate the TCV flow in real time sweeping through the valve to make sure that it is interrogated in its entirety.

The normal TCV waveform demonstrates biphasic pattern of blood flow into the right ventricle. The first one represents diastole and the second one represents the atrial systole (Figs 4 and 5). There should be no flow seen across the valve during the ventricular systole. Since the size of the first trimester heart is quite small the Doppler is often contaminated by the flow in one of the great vessels. The direction of blood flow in the great vessels is the same as that of the regurgitant jet and they are seen at the same point in the cardiac cycle. Therefore, it is imperative to be able to differentiate between the two. There are two consistent differences in their flow pattern. Firstly, the velocity in the great vessels is less than $50 \mathrm{~cm} / \mathrm{sec}$ whereas the velocity of the regurgitant jet is always $>>60 \mathrm{~cm} / \mathrm{sec}$. Therefore, in order to be able to diagnose TCV regurgitation, the blood flow velocity has to be in excess of $60 \mathrm{~cm} / \mathrm{sec}$. Secondly, the regurgitant jet makes a typical high pitched hissing sound on Doppler, which is absent from the flow through the great vessels. It is often this sound that first alerts the operator to the presence of TCV regurgitation. Since a signal from a closing tricuspid valve (Fig. 5A) and trivial tricuspid regurgitation are fairly common findings and are of no clinical significance, regurgitation must last at least 30\% of the ventricular systole in order to be called an abnormal finding. 


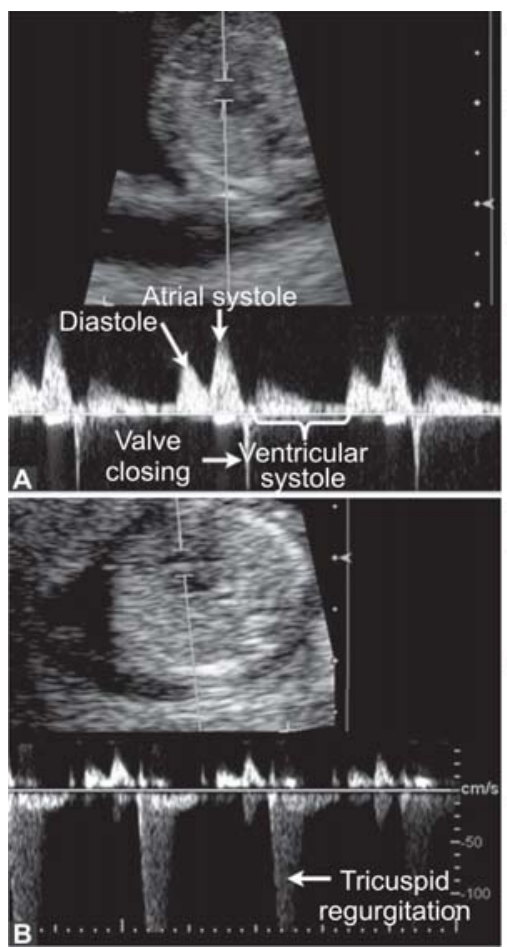

CRL: $45-84 \mathrm{~mm}(11+0$ to $13+6$ weeks' gestation)

Apical four-chamber view of the heart (the apex may be pointing either towards or away from the transducer)

Image size: thorax occupies most of the screen

Pulsed-wave Doppler: the angle of insonation between the Doppler beam and the septum is $\angle 30^{\circ}$; sample gate which is positioned across the TCV should be large (2-3 mm in width)

True tricuspid regurgitation:

Velocity $>60 \mathrm{~cm} / \mathrm{sec}$ to differentiate it from a great vessel waveform

2. Duration $\geq 30 \%$ of the ventricular systole to differentiate it from a signal produced by the closing of the valve

At least three sample volumes need to be obtained to ascertain that the valve is sampled at multiple points as not all of the leaflets are always incompetent

Figs 5A and B: Pulsed Doppler evaluation of the tricuspid valve: normal (A); abnormal (B)

\section{Tricuspid Valve Doppler and Fetal Aneuploidy}

The prevalence of tricuspid regurgitation varies with gestational age. The prevalence of tricuspid regurgitation also increases as the NT measurement increases. ${ }^{11}$ These associations are factored into the algorithm developed by the fetal medicine foundation. It should be noted that tricuspid regurgitation is also associated with an increased risk of congenital heart defects. ${ }^{10}$ Therefore, a careful examination of the fetal heart should be performed at the time when the TCV regurgitation is noted and repeated in the mid second trimester.

Tricuspid regurgitation is seen not only in trisomy 21 but also in trisomies 18 and 13, and monosomy X. The prevalence of tricuspid regurgitation in fetuses with trisomies 21,18 , and 13 and monosomy $\mathrm{X}$ is $56 \%$, 33\%, $30 \%$, and $38 \%$ respectively. The prevalence of tricuspid regurgitation in euploid fetuses is $1 \% .{ }^{11}$ In a study, which included 19, 614 fetuses, a 96\% detection rate for a 3\% false positive rate was achieved for trisomy 21 by adding tricuspid valve evaluation to the combined screen. The detection rates for trisomies 18 and 13, and monosomy $\mathrm{X}$ were $92 \%, 100 \%$, and $100 \%$ respectively. ${ }^{11}$

\section{Reversed a-wave in the Ductus Venosus}

The exact reason for a reversal of the a-wave in the ductus venosus in association with trisomy 21 is also not clear.
However, it is likely that this abnormality is not a result of a change in the DV itself but rather due to a change in the fetal heart performance. Therefore, the ultrastructural changes in the cardiac anatomy described earlier in the "tricuspid valve regurgitation" section may also be responsible for this phenomenon. ${ }^{6,8,118-120}$ However, the abnormality is likely to be the result of decreased compliance of the ventricular walls rather than ventricular dilitation. The mechanical explanation for the a-wave reversal may be that the atrial wall is contracting against a relatively stiffer wall and has to generate more pressure to push the blood across the TCV. The increased back pressure that would be inevitably generated in this situation may be sufficient to either stop or reverse the blood flow during atrial systole (absent or reversed a-wave). In the current FMF algorithm, the DV flow is considered abnormal only if the a-wave is reversed.

\section{Pulsed Doppler Evaluation of Blood Flow through the Ductus Venosus}

The fetus is examined in the longitudinal view slightly to the right of the midline (Figs 6A and B). The DV is identified as a short continuation of the hepatic portion of the umbilical vein (UV). The identification of the DV is greatly aided by using color Doppler. The DV is distinguishable from the UV by a distinctly higher velocity. The pulsed Doppler gate

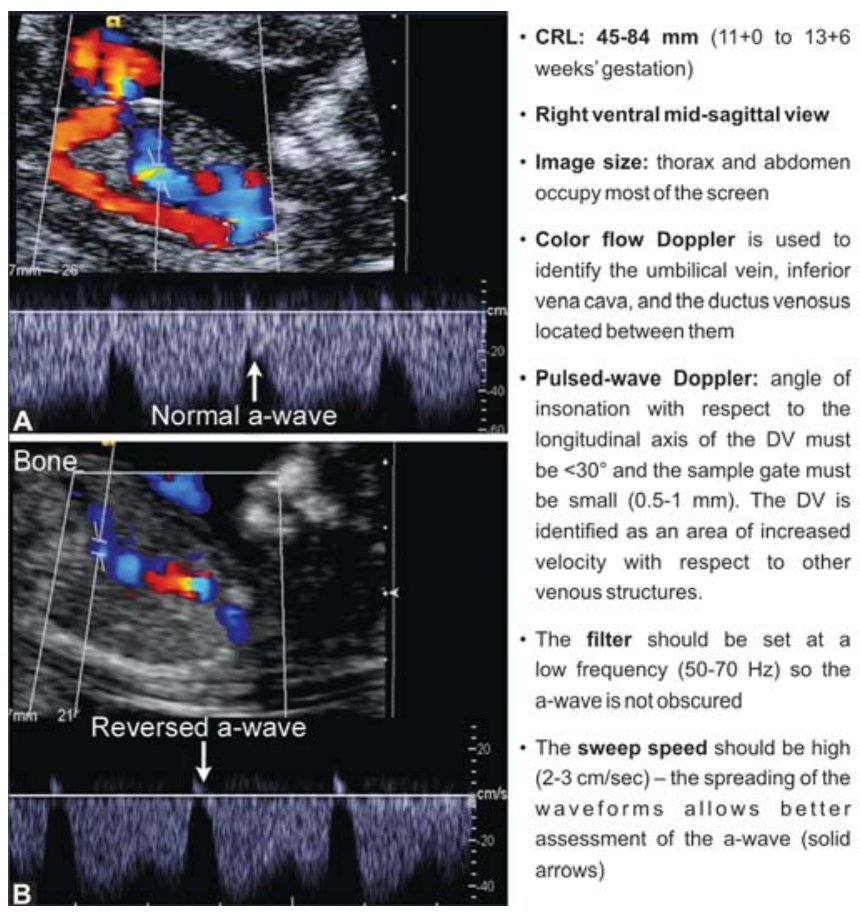

Figs 6A and B: Pulsed Doppler evaluation of the ductus venosus: normal (A); abnormal (B) 
that is placed within the lumen of the DV needs to be small (0.5-1 mm). This is to minimize contamination of the signal by venous structures that are in close proximity such as the hepatic veins and the inferior vena cava. The magnification should be such that the fetal abdomen and thorax fill the majority of the image. The angle of insonation of the Doppler beam should $<30^{\circ}$ with respect to the longitudinal axis of the DV.

On pulsed Doppler, a normal DV waveform demonstrates forward blood flow throughout the cardiac cycle. There are two adjoining periods of increased blood flow: the ventricular systole and the diastole. Normally, the blood flow is diminished during the atrial systole but the forward flow is maintained (Figs 4 and 6).

\section{Ductus Venosus Doppler Flow and Fetal Aneuploidy}

The prevalence of a-wave reversal changes with gestational age. There is also an association in the prevalence of awave reversal and thickening of the NT. These associations are mathematically accounted for in the FMF algorithm. ${ }^{17}$

It should be noted that a-wave abnormalities are also associated with an increased risk of cardiac anomalies. ${ }^{18,19,179}$ Therefore, a careful examination of the fetal heart should be performed at the time when the reversed a-wave is noted and be repeated in the mid second trimester.

Reversed a-wave is seen not only in trisomy 21 but also in trisomies 18 and 13, and monosomy X. The prevalence of tricuspid regurgitation in fetuses with trisomies 21,18 , and 13 and monosomy $\mathrm{X}$ is $66 \%, 58 \%, 55 \%$, and $75 \%$ respectively. The prevalence of reversed a-wave in euploid fetuses is $3 \% .{ }^{17}$ In a study, which included 19,614 fetuses, a $96 \%$ detection rate for a $3 \%$ false positive rate was achieved for trisomy 21 by adding tricuspid valve evaluation to the combined screen. The detection rates for trisomies 18 and 13 , and monosomy $\mathrm{X}$ were $92 \%, 100 \%$, and $100 \%$ respectively. ${ }^{17}$

\section{Fetal Heart Rate in Screening for Aneuploidy}

It has been noted that aneuploid fetuses tend to have different heart rates from the euploid fetuses at the time of the first trimester screening. ${ }^{2,20}$ The largest difference is seen in trisomy 13 and monosomy $\mathrm{X}$ where the heart rate is above the 95 th percentile in $69 \%$ of the cases and $53 \%$ of the cases respectively. The heart rate also tends to be increased in trisomy 21 but much less so (14\% are above the 95th percentile). Both trisomy 18 and triploid fetuses tend to be bradycardic (19\% and 36\% below the 5 th percentile respectively). If FHR is included in first trimester screening, it needs to be adjusted for gestational age as the normal ranges decrease between 11 and $13+6$ weeks of gestation. ${ }^{2,20}$

\section{Acquiring Proficiency in Ultrasound Marker Evaluation}

The proper use of prenatal ultrasound requires appropriate training and experience. This is especially true for the first trimester ultrasound evaluation. It is estimated that a sonographer needs to perform approximately 60 to 80 ultrasound examinations in order to be able to evaluate each of the first trimester markers correctly on consistent basis. ${ }^{182-184}$ However, an improvement in skill is often noticeable even after the first few examinations.

\section{First Trimester Screening for Aneuploidy using Multiple Ultrasound Markers}

The ultrasound markers and maternal serum biochemical markers that are described above are sufficiently independent of each other to be used in combination. This can be done either by evaluating all of them in every fetus, using only some of them in every fetus, or using them on contingent basis. As more markers are added, the detection rate increases and the false positive rate decreases. Mathematical modeling predicts that if all of the ultrasound markers described above are used along with maternal age and maternal serum PAPP-A and free $\alpha$-hCG levels, the detection rate for trisomy 21 would be $96 \%$ for a $2 \%$ false positive rate. ${ }^{3,4,11,17}$

An algorithm using ultrasound markers for aneuploidy on contingent basis in the first trimester was developed by the Fetal Medicine Foundation. ${ }^{139}$ The first step taken in using this approach is to perform the combined screen (maternal age, NT measurement, free $\alpha$-hCG level, PAPPA level) in every patient. Based on the results of the combined screen, the patients are divided into three categories: high risk (trisomy 21 risk of $\geq 1: 50$ ), intermediate risk (trisomy 21 risk of 1:51 to 1:1,000) and low risk category (trisomy 21 risk $<1: 1,000$ ). The patients that fall into the high risk category are offered an invasive diagnostic procedure without any additional screening. This category constitutes only $1.3 \%$ of the total screened population but contains $82 \%$ of the fetuses with trisomy 21 . The low risk group constitutes the majority of the screened population (86.7\%) but contains only $4 \%$ of fetuses with trisomy 21 . These patients are reassured and invasive diagnostic testing is done only upon maternal request. However, a targeted scan at approximately 20 weeks' gestation is still recommended. The intermediate risk category constitutes $12 \%$ of the screened population and includes $14 \%$ of the trisomy 21 fetuses. The persons in this group undergo additional screening by evaluating the additional ultrasound 
markers (NB, FMF angle, TCV, DV). If the resultant risk of trisomy 21 exceeds 1:100, an invasive diagnostic test is offered. If it is less than that, they are treated in the same way as the low risk group.

For a $2 \%$ false positive rate, the detection rate for trisomy 21 using one additional marker is $90 \%$, 94\% for two additional markers, 95\% for three additional markers, and $96 \%$ using all four additional markers. These detection rates are the same whether the contingent approach is used or the additional markers are used in every patient. ${ }^{3,4,11,17,138}$

\section{Variations in Fetal Anatomy as Markers for Aneuploidy (Minor Markers)}

Ultrasound markers for fetal aneuploidy are simply those findings that are seen more commonly in fetuses in the aneuploid population $v s$ the euploid population. These may be divided into two broad categories: "pure" markers and fetal anomalies that act as markers for fetal aneuploidy.

Pure ultrasound markers are those findings that are not detrimental to the fetus per se but are associated with an increased risk of aneuploidy. This group of markers includes the ones discussed above. It also includes a number of other anatomic deviations from the normal (also referred to as "minor markers") that have been shown to increase the risk of fetal aneuploidy even in the first trimester. These include choroid plexus cysts $(>1.5 \mathrm{~mm})$, echogenic intracardiac focus, hyperechogenic bowel, and hydronephrosis (anteroposterior diameter of the renal pelvis $>1.5 \mathrm{~mm}$ ). ${ }^{185}$ These markers are included in the FMF algorithm in screening for trisomy 21. It should be stressed that the minor markers must be interpreted in the context of presence or absence of other markers. The presence of an isolated minor marker probably does not increase the risk of aneuploidy. This is due to the fact that the absence of other markers acts as a counterbalance and decreases the risk sufficiently to negate the effect of the presence of a single marker. ${ }^{185}$

\section{Variations in Fetal Anatomy as Markers for Aneuploidy (Anomalies)}

Fetal anomalies that act as markers for fetal aneuploidy are those fetal defects that not only have a clinical significance in their own right but also increase the risk of an underlying chromosomal defect being present. The ones that are diagnosable in the first trimester and that have a well-defined fixed risks associated with them are the following: holoprosencephaly (risk of 1:2 for trisomy 13), diaphragmatic hernia (risk of 1:4 for trisomy 18), atrioventricular septal defect (risk of 1:2 for trisomy 21), omphalocele (risk of $1: 4$ for trisomy 18 and risk of $1: 10$ for trisomy 13 ), megacystis defined as bladder length of $\geq 7 \mathrm{~mm}$ (risk of 1:10 for either trisomy 18 or 13). ${ }^{186-189}$ The fixed risks associated with these anomalies are also included in the FMF algorithm for aneuploidy risk calculation.

\section{FIRST TRIMESTER SCREENING FOR FETAL ANOMALIES OTHER THAN CHROMOSOMAL DEFECTS}

\section{Nuchal Translucency Measurement as a Marker for Fetal Abnormalities in Chromosomally Normal Fetuses}

Nuchal translucency thickening is associated with an increase in poor pregnancy outcome even if the fetus is chromosomally normal. ${ }^{190-199}$ However, this increase does not become statistically significant until the NT measurement exceeds the 99th percentile. Conveniently, the 99th percentile cut-off remains constant at $3.5 \mathrm{~mm}$ across the $11-13+6$ weeks' gestation period. ${ }^{200}$

A number of different fetal conditions may result in NT thickening making this measurement a useful test across a broad range of fetal anomalies.

\section{Nuchal Translucency Thickening and Fetal Structural Defects}

The prevalence of major fetal abnormalities increases exponentially as the nuchal translucency measurement increases beyond the 99th percentile $(>3.5 \mathrm{~mm})$. The prevalence is approximately $2.5 \%$ for an NT of $3.5 \mathrm{~mm}$ and reaches $45 \%$ for an NT of $6.5 \mathrm{~mm}$ or more. ${ }^{51,201}$

One of the most important areas where NT screening appears to offer an advantage is the prenatal diagnosis of cardiac defects. Cardiac defects are some of the most common congenital structural anomalies but their prenatal diagnosis is in many cases challenging. However, if an accurate prenatal diagnosis of CHD is made, the outcome overall is improved by allowing for the fetus to be delivered in a setting where appropriate neonatal treatment is available. Combined data from a number of screening studies demonstrates that the prevalence of major cardiac defects is 1 to $2 \%$ in fetuses with a $<3.5 \mathrm{~mm}$ NT measurement. A significant increase in the prevalence of CHD is noted with NT measurements $\geq 3.5 \mathrm{~mm}$ : 3\% (3.5-4.5 mm), 7\% (4.5$5.4 \mathrm{~mm}), 20 \%$ (5.4-6.4 mm), 30\% ( $\geq 6.5 \mathrm{~mm}) .^{26,35,38,40-42,190}$

A meta-analysis of screening studies showed a detection rate of 31\% for CHD using an NT measurement of $3.5 \mathrm{~mm}$ as the cut-off. It is estimated that fetal echocardiography in all chromosomally normal fetuses with NT above the 99th percentile would identify one major cardiac defect in every 
16 patients examined. ${ }^{45}$ Furthermore, this analysis showed that an increased NT measurements increase the risk of a variety of heart defects. Results of another study arrived at the same conclusion. ${ }^{202}$ In this multicenter study, nuchal thickening was found to be present in all types of heart defects: left as well as right heart lesions, septal defects, outflow tract disorders, laterality disorders, and complex heart lesions.

With improvements in the resolution of ultrasound equipment, a detailed fetal cardiac evaluation may be performed even in the first trimester of pregnancy. Many of the major cardiac defects may now be diagnosed at the time of the 11-13 + 6 week scan. ${ }^{36,51,89,203,204}$ Even if the specific diagnosis cannot be made, the cardiac examination often will indicate whether or not a cardiac structural defect is present.

There are a number of other types of fetal defects that are seen more commonly in fetuses with NT measurements of $3.5 \mathrm{~mm}$ or greater than in fetuses with normal NT measurements. ${ }^{51-53,201}$ These include diaphragmatic hernia, ${ }^{48}$ omphalocele, ${ }^{47}$ body stalk anomaly, ${ }^{49}$ skeletal defects, ${ }^{54-65}$ and certain genetic syndromes such as congenital adrenal hyperplasia, ${ }^{68}$ fetal akinesia deformation sequence, ${ }^{70}$ Noonan syndrome, ${ }^{66}$ Smith-Lemli-Opitz syndrome, ${ }^{205}$ and spinal muscular atrophy. ${ }^{71,72}$ There are many additional disorders that have been reported in association with a thickened NT that are quite rare. However, in many of these a definite association with a thickened NT is difficult to prove because of their rarity. ${ }^{52}$

Finally, the prevalence of fetal demise is increased in chromosomally normal fetuses in which the NT measurement $\geq 3.5 \mathrm{~mm}$ even if a specific fetal defect cannot be diagnosed. An analysis of 4, 540 fetuses categorized based on the NT measurement showed an increase in intrauterine loss from $1.3 \%$ in the 95th-99th percentile group to $20 \%$ in those that had NT measurements $\geq 6.5 \mathrm{~mm} .{ }^{51,201}$ The majority of fetal losses occur by 20 weeks' gestation. In fetuses that survive to the mid second trimester and in which a targeted ultrasound fails to reveal any anomalies or increased nuchal fold thickness, the risk for perinatal or longterm morbidity and mortality does not appear to be increased. ${ }^{197,198,206-210}$

\section{Screening for Open Neural Tube Defects}

One of the major failings of the first trimester fetal ultrasound examination had been the inability to consistently diagnose open neural tube defects other than the exencephaly/ anencephaly sequence. However, a recently described intracranial marker [intracerebral translucency (IT)] may overcome this deficiency. ${ }^{25}$ The fetal image required to

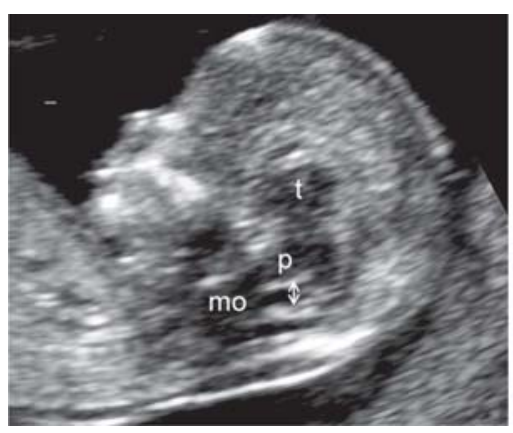

- CRL: $45-84 \mathrm{~mm}(11+0$ to $13+6$
weeks'gestation)
- Mid-sagittal view (fetus may
either be facing towards or away
from the transducer)
- Landmarks on the profile: skin
over the nasal bridge and the nasal
tip (solid arrows)
- Intracranial structures: thalamus
(t), pons (p), medulla oblongata
(mo)
- The intracranial translucency
(double arrow) is located behind
the pons

Fig. 7: Evaluation of the intracranial translucency

evaluate the IT is identical to those needed for the NT, NB and FMF angle evaluation. A magnified midline view of the fetal head and upper thorax is obtained and the following intracranial structures need to be visualized: hypoechoic regions of the thalamus, the pons (brain stem) and the medulla oblongata (Fig. 7). The IT represents the fluid filled fourth ventricle, which is located posteriorly to the pons. The combination of the posterior border of the pons and the floor of the fourth ventricle is seen as a single thin echogenic line, which forms the anterior border of the IT. The posterior border of the IT is the roof of the fourth ventricle. This is seen also as a relatively thin echogenic line accentuated by the choroid plexus of the fourth ventricle.

The IT was consistently visualized and was found to be normal at the $11-13+6$ week scan in the 200 consecutive fetuses that were subsequently shown not to have spina bifida aperta. ${ }^{25}$ In the same study, each of the four fetuses that were diagnosed with spina bifida aperta in the second trimester had an absent first trimester IT (i.e. the fourth ventricle was obliterated). ${ }^{25}$ The proposed mechanism for this finding is similar to that of the Chiari type II malformation ("banana sign") seen in second trimester fetuses with spina bifida aperta: decreased pressure in the subarachnoid spaces leading to the caudal displacement of the brain. It appears that measuring the IT does not provide additional information. Therefore, the IT is simply reported as present or absent.

It would be premature to state that the absence or presence of IT has the same predictive value as the intracranial findings in the second trimester. However, the absence of the IT should lead to an extremely careful ultrasound evaluation of the spine at the time of the first trimester ultrasound. If the appearance of the spine is normal on the initial scan, the fetus should be reexamined at approximately 16 weeks. A 20 week scan should also be performed if the 16 week scan is normal.

\section{First Trimester Screening for Preeclampsia}

It is recognized that the development of preeclampsia is associated with vascular problems within the placental bed. 
Even though the diagnosis of preeclampsia is not made until the second half of the pregnancy, the maldevelopment of the placental bed vessels occurs well before that time. ${ }^{211}$

The resistance of the vascular blood supply to the placenta and the placental bed normally decreases as the pregnancy progresses. This process is inhibited in many of those patients that are destined to develop preeclampsia. Additionally, the different degrees of placental vessel problems may result in a variety pregnancy associated hypertensive disorders: early-onset preeclampsia $[<34$ weeks' gestation, very often associated with intrauterine growth restriction (IUGR)], late-onset preeclampsia ( $\geq 34$ weeks’ gestation), and gestational hypertension.

\section{Pulsed Doppler Evaluation of Blood Flow through the Uterine Arteries}

The impedance of the maternal blood supply to the placental bed may be estimated by measuring the pulsatility index (PI) of the uterine arteries using Doppler ultrasound. It has been shown that the risk of developing preeclampsia increases with increasing uterine artery PI. ${ }^{26-29}$

The first trimester Doppler examination of the uterine artery begins by obtaining a sagittal view of the cervix and the lower uterine segment. The cervical canal and the endocervix are identified. The transducer is then tilted from side to side and the location of the uterine artery at the level of the endocervix is identified with the aid of color Doppler (Fig. 8). The PI is measured using pulsed Doppler with the sample gate set at $2 \mathrm{~mm}$. The angle of insonation with respect to the longitudinal axis of the uterine artery should be less than $30^{\circ}$. The magnification needs to be such that the uterine artery can be identified with confidence and the Doppler may be placed accurately within the lumen. At least three waveforms similar in shape should be obtained and the PI should be measured in both uterine arteries. The lowest PI is used for risk assessment.

In addition to identifying the artery in its proper location, there are two main ways to confirm that the vessel being

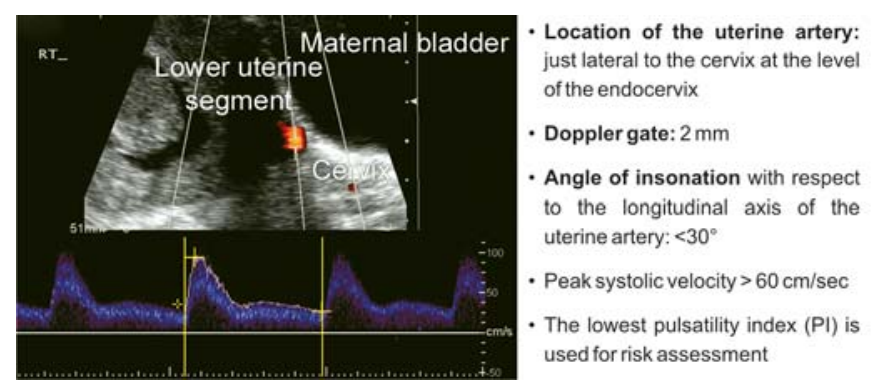

Fig. 8: Pulsed Doppler evaluation of the uterine artery [pulsatility index $(\mathrm{PI})$ measurement] interrogated with Doppler is the uterine artery. Firstly, the direction of the blood flow should be towards the transducer when the transabdominal approach is used. This assures that the cervical branches are not being insonated. Secondly, the peak velocity of the insonated vessel should be $60 \mathrm{~cm} / \mathrm{sec}$ or greater. This assures that the main uterine artery is being insonated rather one of its branches.

\section{Uterine Artery Doppler and Preeclampsia}

Based on a recent publication that included 7,797 patients, it appears that the most efficient method of screening for preeclampsia in the first trimester is based on the following parameters: maternal history, uterine artery pulsatility index (increased PI increases the risk of preeclampsia), mean arterial pressure (increased MAP increases the risk of preeclampsia), pregnancy-associated plasma protein-A (decreased PAPP-A increases the risk of preeclampsia), and placental growth factor (decreased PlGF increases the risk of preeclampsia). ${ }^{26}$ The factors in the maternal history that appear to make a significant independent contribution to the preeclampsia risk assessment included maternal BMI, age, ethnicity, smoking, and parity. For a 5\% false positive rate, the combination of the above mentioned risk factors was shown to predict $90 \%$ of early preeclampsia, 35\% of late preeclampsia, and $20 \%$ of gestational hypertension. ${ }^{26}$ This compares favorably with screening based on maternal history alone where only $30 \%$ of early and $20 \%$ of late preeclampsia are predicted for a 5\% false positive rate.

\section{CONCLUSIONS}

Over the past 40 years, the use of ultrasound has been clearly established as an invaluable tool in obstetric management. There has been a steady increase in our understanding of normal and abnormal fetal physiology along with an improvement in the quality of ultrasound equipment. This has not only lead to our ability to diagnose an ever increasing number of fetal conditions but also has moved the time of diagnosis to an earlier point in pregnancy. This benefits the patient in a number of ways not the least of which is maintaining the maximum level of privacy and preservation of reproductive choices.

The improvements in the screening capabilities of the first trimester scan have lead to an improved detection of fetal abnormalities, especially aneuploidy, and resulted in a decreased false positive rate. The latter has two very important benefits: fewer women have to go through the stress of being told that they fall into the "increased risk" category and fewer women undergo invasive diagnostic procedures. The decrease in the number of invasive diagnostic procedures being performed in turn leads to a 
decrease in cost and a decrease in the number of normal fetuses being lost as a result of the invasive procedures.

Evaluation of maternal blood supply to the uterus along with maternal serum screening and history appears to accurately estimate the risk of developing preeclampsia later in pregnancy. This allows for an improved selection of atrisk patients early in pregnancy and may lead to treatments that reduce the development of preeclampsia in the future.

As the utility of ultrasound examination expands, our responsibility to perform the best possible ultrasound examination increases as well. This can be achieved only with proper training and expertise followed by an ongoing and rigorous external quality assurance program. A factor that is difficult to quantify but is none-the-less crucial in performing a thorough ultrasound examination is a high level of commitment on the part of each individual operator.

\section{REFERENCES}

1. Down LJ. Observations on an ethnic classification of idiots. Clin Lectures and Reports, London Hospital 1866;3:259-62.

2. Kagan KO, Wright D, Valencia C, et al. Screening for trisomies 21,18 and 13 by maternal age, fetal nuchal translucency, fetal heart rate free beta-hCG and pregnancy-associated plasma protein-A. Human Reprod. Sep;23:1968-57. Epub 2008 June 10.

3. Kagan KO, Cicero S, Staboulidou I, et al. Fetal nasal bone in screening for trisomy 21, 18, 13 and Turner syndrome at 11-13 weeks of gestation. Ultrasound in Obstet Gynecol 2009;33: 259-64.

4. Borenstein M, Persico N, Kagan KO, et al. Frontomaxillary facial angle in screening for trisomy 21 at $11+0$ to $13+6$ weeks. Ultrasound Obstet Gynecol 2008;32:5-11.

5. Vis JC, Duffels MGJ, Winter, et al. Down syndrome: A cardiovascular perspective. J Intellect Disabil Res 2009;53:41925. Epub 2009 Feb 18.

6. Recalde AL, Landing BH, Lipsey AI. Increased cardiac muscle size and reduced cell number in Down syndrome. Pediatric Pathol. 1986;6:47-53.

7. Gittenberger-De Groot AC, Bartram U, Oosthoek PW, et al. Collagen type VI expression during cardiac development and in human fetuses with trisomy 21. Anat Rec 2003;275A: 1109-16.

8. Carvalhaes LS, Gervásio OL, Guatimosim C, et al. Collagen $\mathrm{XVIII/endostatin} \mathrm{is} \mathrm{associated} \mathrm{with} \mathrm{the} \mathrm{epithelial-mesenchymal}$ transformation in the atrioventricular valves during cardiac development. Dev Dynamics 2006;235:132-42.

9. Huggon IC, DeFigueiredo DB, Allan LD. Tricuspid regurgitation in the diagnosis of chromosomal anomalies in the fetus at 11-14 weeks of gestation. Heart 2003;89:1071-73.

10. Faiola S, Tsoi E, Huggon IC, et al. Likelihood ratio for trisomy 21 in fetuses with tricuspid regurgitation at the 11 to $13+6$ week scan. Ultrasound Obstet Gynecol 2005;26:22-27.

11. Kagan KO, Valencia C, Livanos $P$, et al. Tricuspid regurgitation in screening for trisomies 21, 18 and 13 and Turner syndrome at $11+0$ to $13+6$ weeks of gestation. Ultrasound Obstet Gynecol 2009;33:18-22.
12. Maiz N, Valencia C, Emmanuel EE, et al. Screening for adverse pregnancy outcome by ductus vensous Doppler at 11-13+6 weeks of gestation. Obstet Gynecol 2008;112:598-605.

13. Mavrides E, Sairam S, Hollis B, et al. Screening for aneuploidy in the first trimester by assessment of blood flow in the ductus venosus. Br J Obstet Gynaecol 2002;109:1015-19.

14. Murta CG, Moron AF, Avila MA, et al. Application of ductus venosus Doppler elocimetry for the detection of fetal aneuploidy in the first trimester of pregnancy. Fetal Diagn Ther 2002;1: 308-14.

15. Zoppi MA, Putzolu M, Ibba RM, et al. First-trimester ductus venosus velocimetry in relation to nuchal translucency thickness and fetal karyotype. Fetal Diagn Ther 2002;17:52-57.

16. Borrell A, Martinez JM, Seres A, et al. Ductus venosus assessment at the time of nuchal translucency measurement in the detection of fetal aneuploidy. Prenat Diagn 2003;23: 921-26.

17. Maiz N, Valencia C, Kagan KO, et al. Ductus venosus Doppler in screening for trisomies 21, 18, and 13 and Turner syndrome at 11-13 weeks of gestation. Ultrasound Obstet Gynecol 2009;33:512-17.

18. Bilardo CM, Muller MA, Zikulnig L, et al. Ductus venosus studies in fetuses at high risk for chromosomal or heart abnormalities: Relationship with nuchal translucency measurement and fetal outcome. Ultrasound Obstet Gynecol 2001; 17:288-94.

19. Maiz N, Plasencia W, Daklis T, et al. Ductus venosus Doppler in fetuses with cardiac defects and increased nuchal translucency thickness. Ultrasound Obstet Gynecol 2008;31:256-60.

20. Liao AW, Snijders R, Geerts L, et al. Fetal heart rate in chromosomally abnormal fetuses. Ultrasound Obstet Gynecol 2000;16:610-13.

21. Spencer K, Souter V, Tul N, et al. A screening program for trisomy 21 at 10 to 14 weeks using fetal nuchal translucency, maternal serum free ß-human chorionic gonadotropin and pregnancy-associated plasma protein-A. Ultrasound Obstet Gynecol 1999;13:231-37.

22. Spencer K. Aneuploidy screening in the first trimester. Am J Med Genet Part C Semin Med Genet. 2007;145C:18-32.

23. Borenstein M, Persico N, Dagklis T, et al. Frontomaxillary facial angle in fetuses with trisomy 13 at $11+0$ to $13+6$ weeks. Ultrasound Obstet Gynecol 2007;30:819-23.

24. Borenstein M, PersicoN, Strobl I, et al. Frontomaxillary and mandibulomaxillary facial angles at $11+0$ to $13+6$ weeks in fetuses with trisomy 18. Ultrasound Obstet Gynecol 2007; 30:928-33.

25. Chaoui R, Benoit B, Mitkowska-Wozniak K, et al. Assessment of intracranial translucency (IT) in the detection of spina bifida at the 11-13 week scan. Ultrasound Obstet Gynecol 2009;34: 249-52.

26. Poon LCY, Kametas NA, Chelemen T, et al. Maternal risk factors for hypertensive disorders in pregnancy: A multivariate approach. J Hum Hypertens. 2010;24:104-10.

27. Poon LCY, Staboulidou I, Maiz N, et al. Hypertensive disorders in pregnancy: Screening by uterine artery Doppler at 11-13 weeks. Ultrasound Obstet Gynecol 2009;34:142-48.

28. Poon LC, Stratieva V, Piras S, et al. Hypertensive disorders in pregnancy: Combined screening by uterine Doppler, blood pressure and serum PAPP-A at 11-13 weeks. Prenat Diagn Epub 2010 Jan 27. 
29. Poon LCY, Karagiannis G, Leal A, et al. Hypertensive disorders in pregnancy: Screening by uterine artery Doppler and blood pressure at 11-13 weeks. Ultrasound Obstet Gynecol 2009;34:487-502.

30. Cuckle H, Benn P, Wright D. Down syndrome screening in the first and/or second trimester: Model predicted performance using meta-analysis parameters. Semin Perinatol 2005;29:252-57.

31. Hyett J, Moscoso G, Papapanagiotou G, et al. Abnormalities of the heart and great arteries in chromosomally normal fetuses with increased nuchal translucency thickness at 11-13 weeks of gestation. Ultrasound Obstet Gynecol 1996;7:245-50.

32. Schwarzler P, Carvalho JS, Senat MV, et al. Screening for fetal aneuploidies and fetal cardiac abnormalities by nuchal translucency thickness measurement at 10-14 weeks of gestation as part of routine antenatal care in an unselected population. $\mathrm{Br}$ J Obstet Gynaecol 1999;106:1029-34.

33. Bahado-Singh RO, Wapner R, Thom E, et al. Elevated firsttrimester nuchal translucency increases the risk of congenital heart defects. Am J Obstet Gynecol 2005;192:1357-61.

34. Moselhi M, Thilaganathan B. Nuchal translucency: A marker for the antenatal diagnosis of aortic coarctation. Br J Obstet Gynaecol 1996;103:1044-45.

35. Hyett JA, Perdu M, Sharland GK, et al. Increased nuchal translucency at 10-14 weeks of gestation as a marker for major cardiac defects. Ultrasound Obstet Gynecol 1997;10:242-46.

36. Zosmer N, Souter VL, Chan CSY, et al. Early diagnosis of major cardiac defects in chromosomally normal fetuses with increased nuchal translucency. Br J Obstet Gynaecol 1999;106:829-33.

37. Ghi T, Huggon IC, Zosmer N, et al. Incidence of major structural cardiac defects associated with increased nuchal translucency but normal karyotype. Ultrasound Obstet Gynecol 2001;18: 610-14.

38. Lopes LM, Brizot ML, Lopes MA, et al. Structural and functional cardiac abnormalities identified prior to 16 weeks' gestation in fetuses with increased nuchal translucency. Ultrasound Obstet Gynecol 2003;22:470-78.

39. Galindo A, Comas C, Martinez JM, et al. Cardiac defects in chromosomally normal fetuses with increased nuchal translucency at 10-14 weeks of gestation. J Matern Fetal Neonatal Med 2003;13:163-70.

40. McAuliffe F, Winsor S, Hornberger L, et al. Fetal cardiac defects and increased nuchal translucency thickness. Am J Obstet Gynecol 2003;189, Abstract 571.

41. Hyett J, Perdu M, Sharland G, et al. Using fetal nuchal translucency to screen for major congenital cardiac defects at 10-14 weeks of gestation: Population based cohort study. British Medical Journal 1999;318:81-85.

42. Mavrides E, Cobian-Sanchez F, Tekay A, et al. Limitations of using first trimester nuchal translucency measurement in routine screening for major congenital heart defects. Ultrasound Obstet Gynecol 2001;17:106-10.

43. Orvos H, Wayda K, Kozinsky Z, et al. Increased nuchal translucency and congenital heart defects in euploid fetuses. The Szeged experience. Eur J Obstet Gynecol Reprod Biol 2002;101:124-28.

44. Hafner E, Schuller T, Metzenbauer M, et al. Increased nuchal translucency and congenital heart defects in a low-risk population. Prenat Diagn 2003;23:985-89.
45. Makrydimas G, Sotiriadis A, Ioannidis JP. Screening performance of first-trimester nuchal translucency for major cardiac defects: A meta-analysis. Am J Obstet Gynecol 2003;189:1330-35.

46. Hyett J, Moscoso G, Papapanagiotou G, et al. Abnormalities of the heart and great arteries in chromosomally normal fetuses with increased nuchal translucency thickness at 11-13 weeks of gestation. Ultrasound Obstet Gynecol 1996;7:245-50.

47. Schemm S, Gembruch U, Germer U, et al. Omphaloceleexstrophy-imperforate anus-spinal defects (OEIS) complex associated with increased nuchal translucency.Ultrasound Obstet Gynecol 2003;22:95-97.

48. Sebire NJ, Snijders RJM, Davenport M, et al. Fetal nuchal translucency thickness at 10-14 weeks of gestation and congenital diaphragmatic hernia. Obstet Gynecol 1997;90:943-47.

49. Smrcek JM, Germer U, Krokowski M, et al. Prenatal ultrasound diagnosis and management of body stalk anomaly: Analysis of nine singleton and two multiple pregnancies. Ultrasound Obstet Gynecol 2003;21:322-28.

50. Monteagudo A, Mayberry P, Rebarber A, et al. Sirenomelia sequence: First-trimester diagnosis with both two- and threedimensional sonography. Ultrasound Med 2002;21:915-20.

51. Souka AP, Snidjers RJM, Novakov A, et al. Defects and syndromes in chromosomally normal fetuses with increased nuchal translucency at 10-14 weeks of gestation. Ultrasound Obstet Gynecol 1998;11:391-400.

52. Souka A, Heath V. Increased nuchal translucency with normal karyotype. In Sebire NJ, Snijders RJM, Nicolaides KH (Eds). The 11-14 week scan: Diagnosis of fetal abnormalities. Carnforth, UK: Parthenon Publishing; 1999;67-88.

53. Souka A, von Kaisenberg C, Hyett J, et al. Increased nuchal translucency with normal karyotype. Am J Obstet Gynecol April 2005;192:1005-21.

54. Ben Ami M, Perlitz Y, Haddad S, et al. Increased nuchal translucency is associated with asphyxiating thoracic dysplasia. Ultrasound Obstet Gynecol 1997;10:297-98.

55. Soothill PW, Vuthiwong C, Rees H. Achondrogenesis type 2 diagnosed by transvaginal ultrasound at 12 weeks of gestation. Prenat Diagn 1993;13:523-28.

56. Makrydimas G, Souka A, Skentou H, et al. Osteogenesis imperfecta and other skeletal dysplasias presenting with increased nuchal translucency in the first trimester. Am J Med Genet 2001;98:117-20.

57. Fisk NM, Vaughan J, Smidt M, et al. Transvaginal ultrasound recognition of nuchal oedema in the first-trimester diagnosis of achondrogenesis. J Clin Ultrasound 1991;19:586-90.

58. Meizner I, Barnhard Y. Achondrogenesis type I diagnosed by transvaginal ultrasonography at 13 weeks' gestation. Am J Obstet Gynecol 1995;173:1620-22.

59. den Hollander NS, van der Harten HJ, Vermeij-Keers C, et al. First trimester diagnosis of Blomstrand lethal osteochondrodysplasia. Am J Med Genet 1997;73:345-50.

60. Souka AP, Raymond FL, Mornet E, et al. Hypophosphatasia associated with increased nuchal translucency: A report of three consecutive pregnancies. Ultrasound Obstet Gynecol 2002; 20:294-95.

61. Eliyahu S, Weiner E, Lahav D, et al. Early sonographic diagnosis of Jarcho-Levin syndrome: A prospective screening program in one family. Ultrasound Obstet Gynecol 1997;9:314-18. 
62. Souter V, Nyberg D, Siebert JR, et al. Upper limb phocomelia associated with increased nuchal translucency in a monochorionic twin pregnancy J Ultrasound Med 2002;21:355-60.

63. Petrikovsky BM, Gross B, Bialer M, et al. Prenatal diagnosis of pseudothalidomide syndrome in consecutive pregnancies of a consanguineous couple. Ultrasound Obstet Gynecol 1997; 10:4252-28.

64. Percin EF, Guvenal T, Cetin A, et al. First-trimester diagnosis of Robinow syndrome. Fetal Diagn Ther 2001;16:308-11.

65. Hill LM, Leary J. Transvaginal sonographic diagnosis of shortrib polydactyly dysplasia at 13 weeks' gestation. Prenat Diagn 1998;18:1198-201.

66. Achiron R, Heggesh J, Grisaru D, et al. Noonan syndrome: A cryptic condition in early gestation. Am J Med Genet 2000;92:159-65.

67. Souka AP, Krampl E, Geerts L, et al. Congenital lymphedema presenting with increased nuchal translucency at 13 weeks of gestation. Prenat Diagn 2002;22:91-92.

68. Fincham J, Pandya PP, Yuksel B, et al. Increased first-trimester nuchal translucency as a prenatal manifestation of salt-wasting congenital adrenal hyperplasia. Ultrasound Obstet Gynecol 2002;20:392-94.

69. Souka AP, Skentou H, Geerts L, et al. Congenital nephrotic syndrome presenting with increased nuchal translucency in the first trimester. Prenat Diagn 2002;22:93-95.

70. Hyett J, Noble P, Sebire NJ, et al. Lethal congenital arthrogryposis presents with increased nuchal translucency at 10-14 weeks of gestation. Ultrasound Obstet Gynecol 1997;9:310-13.

71. Rijhsinghani A, Yankowitz J, Howser D, et al. Sonographic and maternal serum screening abnormalities in fetuses affected by spinal muscular atrophy. Prenat Diagn 1997;17:166-69.

72. de Jong-Pleij EA, Stoutenbecek P, van der Mark-Batseva NN, et al. The association of spinal muscular atrophy type II and increased nuchal translucency. Ultrasound Obstet Gynecol 2002;19:312-13.

73. Lam YH, Tang MH, Lee CP, et al. Nuchal translucency in fetuses affected by homozygous a-thalassemia-1 at 12-13 weeks of gestation. Ultrasound Obstet Gynecol 1999;13:238-40.

74. Souka AP, Bower S, Geerts L, et al. Blackfan-Diamond anemia and dyserythropoietic anemia presenting with increased nuchal translucency at 12 weeks of gestation. Ultrasound Obstet Gynecol 2002;20:197-99.

75. Pannier E, Viot G, Aubry MC, et al. Congenital erythropoietic porphyria (Gunther's disease): Two cases with very early prenatal manifestation and cystic hydroma. Prenat Diagn 2003;23: 25-30.

76. Tercanli S, Miny P, Siebert MS, et al. Fanconi anemia associated with increased nuchal translucency detected by first-trimester ultrasound. Ultrasound Obstet Gynecol 2001;17:160-62.

77. Petrikovsky BM, Baker D, Schneider E. Fetal hydrops secondary to human parvovirus infection in early pregnancy. Prenat Diagn 1996;16:342-44.

78. Markenson G, Correia LA, Cohn G, et al. Parvoviral infection associated with increased nuchal translucency: A case report. J Perinatol 2000;20:129-31.

79. Smulian JC, Egan JF, Rodis JF. Fetal hydrops in the first trimester associated with maternal parvovirus infection. J Clin Ultrasound 1998;26:314-16.
80. Becker R, Wegner RD. Detailed screening for fetal anomalies and cardiac defects at the 11-13 week scan. Ultrasound Obstet Gynecol 2006;27:613-18.

81. Green JJ, Hobbins JC. Abdominal ultrasound examination of the first trimester fetus. Am J Obstet Gynecol 1988;159: 165-75.

82. Rottem S, Bronshtein M, Thaler I, et al. First trimester transvaginal sonographic diagnosis of fetal anomalies. Lancet 1989;1:444-45

83. Johnson P, Sharland G, Maxwell D, et al. The role of transvaginal sonography in the early detection of congenital heart disease. Ultrasound Obstet Gynecol 1992;2:248-51.

84. Braithwaite JM, Armstrong MA, Economides DL. Assessment of fetal anatomy at 12 to 13 weeks of gestation by transabdominal and transvaginal sonography. Br J Obstet Gynaecol 1996;103: 82-85.

85. Hernadi L, Torocsik M. Screening for fetal anomalies in the 12th week of pregnancy by transvaginal sonography in an unselected population. Prenat Diagn 1997;17:753-59.

86. Economides DL, Braithwaite JM. First trimester ultrasonographic diagnosis of fetal structural abnormalities in a low risk population. Br J Obstet Gynaecol 1998;105:53-57.

87. Carvalho MH, Brizot ML, Lopes LM, et al. Detection of fetal structural abnormalities at the 11-14 week ultrasound scan. Prenat Diagn 2002;22:1-4.

88. Souka AP, Pilalis A, Kavalakis I, et al. Screening for major structural abnormalities at the 11- to 14-week ultrasound scan. Am J Obstet Gynecol 2006;194:393-96.

89. Gembruch U, Knopfle G, Bald R, et al. Early diagnosis of fetal congenital heart disease by transvaginal echocardiography. Ultrasound Obstet Gynecol 1993;3:310-17.

90. Achiron R, Rotstein Z, Lipitz S, et al. First-trimester diagnosis of fetal congenital heart disease by transvaginal ultrasonography. Obstet Gynecol 1994;84:69-72.

91. Smrcek JM, Gembruch U, Krokowski M, et al. The evaluation of cardiac biometry in major cardiac defects detected in early pregnancy. Arch Gynecol Obstet 2003;268:94-101.

92. Wisser J, Dirschedl P, Krone S. Estimation of gestational age by transvaginal sonographic measurements of greatest embryonic length in dated human embryos. Ultrasound Obstet Gynecol 1994;4:457-62.

93. Monteagudo A, Timor-Tritsch I, Sharma S. Early and simple determination of chorionic and amniotic type in multifetal gestations in the first 14 weeks by high frequency transvaginal ultrasound. Am J Obstet Gynecol 1994;170:824-29.

94. Sepulveda W, Sebire NJ, Hughes K, et al. The lambda sign at 10-14 weeks of gestation as a predictor of chorionicity in twin pregnancies. Ultrasound Obstet Gynecol 1996;7:421-23.

95. Selpuveda W, Sebire NJ, Hughes K, et al. Evolution of the lambda or twin/chorionic peak sign in dichorionic twin pregnancies. Obstet Gynecol 1997;89:439-41.

96. Noble PL, Snijders RJM, Abraha HD, et al. Maternal serum free beta-hCG at 10 to 14 weeks in trisomic twin pregnancies. Br J Obstet Gynaecol 1997;104:741-43.

97. Spencer K. Screening for trisomy 21 in twin pregnancies in the first trimester using free beta-hCG and PAPP-A, combined with fetal nuchal translucency thickness. Prenat Diagn 2000;20: 91-95. 
98. Spencer K, Nicolaides KH. Screening for trisomy 21 in twins using first trimester ultrasound and maternal serum biochemistry in a one-stop clinic: A review of three years experience. BJOG 2003;110:276-80.

99. Kagan KO, Gassoni A, Selpuveda-Gonzalez G, et al. Discordance in nuchal translucency thickness in the prediction of severe twin-to-twin transfusion syndrome. Ultrasound Obstet Gynecol 2007;29:527-32.

100. Maiz N, Staboulidou I, Leal AM, et al. Ductus venosus Doppler at 11 to 13 weeks of gestation in the prediction of outcome in twin pregnancies. Obstet Gynecol 2009;113:860-65.

101. Souka AP, Pilalis A, Kavalakis Y, et al. Assessment of fetal anatomy at the 11-14 week ultrasound examination. 2004; 24:730-34

102. van Zalen-Sprock RM, van Vugt JMG, van Geijn HP. Firsttrimester sonography of physiological midgut herniation and early diagnosis of omphalocele. Prenat Diagn 1997;17:511-18.

103. Snijders RJ, Sebire NJ, Souka A, et al. Fetal exomphalos and chromosomal defects: Relationship to maternal age and gestation. Ultrasound Obstet Gynecol 1995;6:250-55.

104. van Zalen-Sprock RM, van Vugt JMG, van Geijn HP. Firsttrimester sonography of physiological midgut herniation and early diagnosis of omphalocele. Prenat Diagn 1997;17:511-18.

105. Johnson SP, Sebire NJ, Snijders RMJ, et al. Ultrasound screening for anecephaly at 10-14 weeks of gestation. Ultrasound Obstet Gynecol 1997;9:14-16.

106. Sandikcioglu M, Molsted K, Kjaer I. The prenatal development of the human nasal and vomeral bones. J Craniofac Genet Dev Biol 1994;14:124-34.

107. Makikallio K, Jouppila P, Rasanen J. Human fetal cardiac function during the first trimester of pregnancy. Heart 2005;91:443-48.

108. Wright D, Kagan KO, Molina FS, et al. A mixture model of nuchal translucency thickness in screening for chromosomal defects. Ultrasound Obstet Gynecol. 2008;31:376-83.

109. Whitlow BJ, Economides DL. The optimal gestational age to examine fetal anatomy and measure nuchal translucency in the first trimester. Ultrasound Obstet Gynecol 1998;11:258-61.

110. Mulvey S, Baker L, Edwards A, et al. Optimizing the timing for nuchal translucency measurement. Prenat Diagn 2002;22: 775-77.

111. Nicolaides KH, Brizot ML, Snijders RJM. Fetal nuchal translucency: Ultrasound screening for fetal trisomy in the first trimester. Br J Obstet Gynaecol 1994;101:782-86.

112. Uehara S, Yaegashi N, Maeda T, et al. Risk of recurrence of fetal chromosomal aberration: Analysis of trisomy 21, trisomy 18, trisomy 13, and $45 \mathrm{X}$, in 1,076 Japanese mothers. J Obstet Gynaecol Res 1999;25:373-79.

113. Nicolaides KH, Azar G, Byrne D, et al. Fetal nuchal translucency: Ultrasound screening for chromosomal defects in first trimester of pregnancy. Br Med J 1992;304:867-89.

114. Simpson JM, Sharland GK. Nuchal translucency and congenital heart defects: Heart failure or not? Ultrasound Obstet Gynecol 2000;16:30-36.

115. Rizzo G, Muscatello A, Angelini E, et al. Abnormal cardiac function in fetuses with increased nuchal translucency. Ultrasound Obstet Gynecol 2003;21:539-42.

116. Hyett JA, Brizot ML, von Kaisenberg CS, et al. Cardiac gene expression of atrial natriuretic peptide and brain natriuretic peptide in trisomic fetuses. Obstet Gynecol 1996;87:506-10.
117. Tsuchimochi H, Kurimoto F, Leki K, et al. Atrial natriuretic peptide distribution in fetal and failed adult human hearts. Circulation 1988;78:920-27.

118. von Kaisenberg CS, Krenn V, Ludwig M, et al. Morphological classification of nuchal skin in fetuses with trisomy 21, 18 and 13 at 12-18 weeks and in a trisomy 16 mouse. Anat Embryol 1998;197:105-24.

119. von Kaisenberg CS, Brand-Saberi B, Christ B, et al. Collagen type VI gene expression in the skin of trisomy 21 fetuses. Obstet Gynecol 1998;91:319-23.

120. Bohlandt S, von Kaisenberg CS, Wewetzer K, et al. Hyaluronan in the nuchal skin of chromosomally abnormal fetuses. Hum Reprod 2000;15:1155-58.

121. Chitayat D, Kalousek DK, Bamforth JS. Lymphatic abnormalities in fetuses with posterior cervical cystic hygroma. Am J Med Genet 1989;33:352-56

122. von Kaisenberg CS, Nicolaides KH, Brand-Siberi B. Lymphatic vessel hypoplasia in fetuses with Turner syndrome. Hum Reprod 1999; 14:823.

123. Nicolaides KH, Rodeck $\mathrm{CH}$, Lange I, et al. Fetoscopy in the assessment of unexplained fetal hydrops. Br J Obstet Gynaecol 1985;92:671-79.

124. Sohan K, Carroll S, Byrne D, et al. Parvovirus as a differential diagnosis of hydrops fetalis in the first trimester. Fetal Diagn Ther 2000;15:234-36.

125. Braithwaite JM, Morris RW, Economides DL. Nuchal translucency measurements: Frequency, distribution, and changes with gestation in a general population. $\mathrm{Br} \mathrm{J}$ Obstet Gynaecol 1996;103:1201-04.

126. Whitlow BJ, Chatzipapas IK, Economides DL. The effect of fetal neck position on nuchal translucency measurement at 1014 weeks. Br J Obstet Gynaecol 1998;105:872-76.

127. Shaefer M, Laurichesse-Delmas H, Ville Y. The effect of nuchal cord on nuchal translucency measurement at 10-14 weeks. Ultrasound Obstet Gynecol 1998;11:271-73.

128. Molina F, Avgidou K, Kagan K, et al. Cystic hygromas, nuchal edema, and nuchal translucency at 11-14 weeks of gestation. Obstet. Gynecol 2006;107:678-83.

129. Malone FD, Ball RH, Nyberg DA, et al. for the FASTER Trial Research Consortium. First Trimester Septated Cystic Hygroma: Prevalence, Natural History, and Pediatric Outcome. Obstet Gynecol 2005;106:288-94.

130. Sonek J, Croom C, McKenna D, et al. Letter to the Editor, Obstet Gynecol 2006;107:424.

131. Comstock CH, Malone FD, Ball RH, Nyberg DA, et al. For the FASTER Research Consortium. Is there a nuchal translucency millimeter measurement above which there is no added benefit from first trimester serum screening? Am J Obstet Gynecol 2006;195:843-47.

132. Snijders RJM, Noble P, Sebire N, et al. UK multicentre project on assessment of risk of trisomy 21 by maternal age and fetal nuchal translucency thickness at 10-14 weeks of gestation. Lancet 1998;351:343-46.

133. Hewitt BG, de Crespigny L, Sampson AJ, et al. Correlation between nuchal thickness and abnormal karyotype in first trimester fetuses. Med J Aust 1996;165:365-68.

134. Snijders RJ, Johnson S, Sebire NJ, et al. First-trimester ultrasound screening for chromosomal defects. Ultrasound Obstet Gynecol. 1996;7:216-26. 
135. Pajkrt E, van Lith JMM, Mol BWJ, et al. Screening for Down’s syndrome by fetal nuchal translucency measurement in a general obstetric population. Ultrasound Obstet Gynecol 1998;12: 163-69.

136. Spencer K, Spencer DE, Power M, et al. Screening for chromosomal abnormalities in the first trimester using ultrasound and maternal serum biochemistry and in a one-stop clinic: A review of three years prospective experience. $\mathrm{Br} \mathrm{J}$ Obstet Gynaecol 2003;110:281-86.

137. Kagan KO, Wright D, Baker A, et al. Screening for trisomy 21 by maternal age, fetal nuchal translucency thickness, free beta human chorionic gonadotropin and pregnancy-associated plasma protein-A. Ultrasound Obstet Gynecol 2008;31:618-24.

138. Kagan KO, Etchegaray A, Zhou Y, et al. Prospective validation of first-trimester combined screening for trisomy 21. Ultrasound Obstet Gynecol 2009;34:14-18.

139. Nicolaides KH, Spencer K, Avgidou K, et al. Multicenter study of first-trimester screening for trisomy 21 in 75821 pregnancies: Results and estimation of the potential impact of individual riskorientated two-stage first-trimester screening. Ultrasound Obstet Gynecol 2005;25:221-26.

140. Avgidou K, Papageorghiou A, Bindra R, et al. Prospective firsttrimester screening for trisomy 21 in 30,564 pregnancies. Am J Obstet Gynecol 2005;192:1761-67.

141. Kagan KO, Anderson JM, Anwandter G, et al. Screening for triploidy by the risk algorithms for trisomies 21, 18 and 13 at 11-13weeks and 6 days of gestation. Prenat Diagn 2008;28: 1209-13.

142. Kagan KO, Wright D, Maiz N, et al. Screening for trisomy 18 by maternal age, fetal nuchal translucency, free beta-human chorionic gonadotropin and pregnancy-associated plasma protein-A. Ultrasound Obstet Gynecol 2008;4:488-92.

143. Farkas LG, Katic MJ, Forrest CR, et al. Surface anatomy of the face in Down's syndrome: Linear and angular measurements in the craniofacial regions. J Craniofac Surg 2001;12:373-79.

144. Keeling JW, Hansen BF, Kjaer I. Pattern of malformation in the axial skeleton in human trisomy 21 fetuses. Am J Med Genet 1997;68:466-71.

145. Stempfle N, Huten Y, Fredouille C, et al. Skeletal abnormalities in fetuses with Down's syndrome: A radiologic postmortem study. Pediatr Radiol 1999;29:682-88.

146. Tuxen A, Keeling JW, Reintoft I, et al. A histological and radiological investigation of the nasal bone in fetuses with Down syndrome. Ultrasound Obstet Gynecol 2003;22:22-26.

147. Minderer S, Gloning KP, Henrich W, et al. The nasal bone in fetuses with trisomy 21: Sonographic versus pathomorphological findings. Ultrasound Obstet Gynecol 2003;22:16-21.

148. Sonek J, Cicero S, Neiger R, et al. Nasal bone assessment in prenatal screening for trisomy 21. Am J Obstet Gynecol 2006;195:1219-30.

149. Sonek J, Nicolaides K. Prenatal ultrasonographic diagnosis of nasal bone abnormalities in three fetuses with Down syndrome. Am J Obstet Gynecol 2002;186:139-41.

150. Mentz RG, Engel U, Kjaer I. Nasal bone length in trisomy 18, triploidy and Turner syndrome analyzed on postmortem radiographs.(letter to the editor) Ultrasound Obstet Gynecol 2009;34:605-08.

151. Cicero S, Curcio P, Papageorghiou A, et al. Absence of nasal bone in fetuses with Trisomy 21 at 11-14 weeks of gestation: An observational study. Lancet 2001;358:1665-67.
152. Otano L, Aiello H, Igarzabal L, et al. Association between first trimester absence of fetal nasal bone on ultrasound and Down's syndrome. Prenat Diagn 2002;22:930-32.

153. Zoppi MA, Ibba RM, Axinan C, et al. Absence of fetal nasal bone and aneuploidies at first-trimester nuchal translucency screening in unselected pregnancies. Prenat Diagn 2003;23:496500.

154. Viora E, Masturzo B, Errante G, et al. Ultrasound evaluation of fetal nasal bone at 11 to 14 weeks in a consecutive series of 1906 fetuses. Prenat Diagn 2003;23:784-87.

155. Wong SF, Choi H, Ho LC. Nasal bone hypoplasia: Is it a common finding amongst chromosomally normal fetuses of southern Chinese women? Gynecol Obstet Invest 2003;56: 99-101.

156. Cicero S, Longo D, Rembouskos G, et al. Absent nasal bone at 11-14 weeks of gestation and chromosomal defects. Ultrasound Obstet Gynecol 2003;22:31-35.

157. Cicero S, Bindra R, Rembouskos G, et al. Fetal nasal bone length in chromosomally normal and abnormal fetuses at 11-14 weeks of gestation. J Matern Fetal Neonatal Med 2002;11:400-02.

158. Rembouskos G, Cicero S, Longo D, et al. Assessment of the fetal nasal bone at 11-14 weeks of gestation by three-dimensional ultrasound. Ultrasound Obstet Gynecol 2004;23:232-36.

159. Cicero S, Rembouskos G, Vandecruys H, et al. Likelihood ratio for Trisomy 21 in fetuses with absent nasal bone at the 11-14 weeks scan. Ultrasound Obstet Gynecol 2004;23:218-23.

160. Cicero S, Bindra R, Rembouskos G, et al. Integrated ultrasound and biochemical screening for trisomy 21 using nuchal translucency, absent fetal nasal bone, free beta-hCG, and PAPPA at 11 to 14 weeks of gestation. Prenat Diagn 2003;23:306-10.

161. Cicero S, Avgidu K, Rembouskos G, et al. Nasal bone assessment in prenatal screening for trisomy 21. Am J Obstet Gynecol 2006;195:109-14.

162. Sonek J, Borenstein M, Dagklis T, et al. Frontomaxillary facial angle in fetuses with trisomy 21 at 11-13 (+6) weeks'. Am J Obstet Gynecol 2007;196(3):271.e1-4.

163. Plasencia W, Dagklis T, Pachoumi C, et al. Frontomaxillary facial angle at $11+0$ to $13+6$ weeks: Effect of plane of acquisition. Ultrasound Obstet Gynecol 2007;29:660-65.

164. Sonek J, Borenstein M, Downing C, et al. Frontomaxillary facial angles in screening for trisomy 21 at 14-23 weeks' gestation. Am J Obstet Gynecol 2007;197:160.e1-5

165. Borenstein M, Persico N, Kaihura C, et al. Frontomaxillary facial angle in chromosomally normal fetuses at $11+0$ to $13+6$ weeks. Ultrasound Obstet Gynecol 2007;30:737-41.

166. Borenstein M, Persico N, Dagklis T, et al. Frontomaxillary facial angle in fetuses with trisomy 13 at $11+0$ to $13+6$ weeks. Ultrasound Obstet Gynecol 2007;30:819-23.

167. Borenstein M, PersicoN, Strobl I, et al. Frontomaxillary and mandibulomaxillary facial angles at $11+0$ to $13+6$ weeks in fetuses with trisomy 18. Ultrasound Obstet Gynecol 2007; 30:928-33.

168. Falcon O, Auer M, Gerovassili A, et al. Screening for trisomy 21 by tricuspid regurgitation, nuchal translucency and maternal serum free $\beta$-hCG and PAPP-A at $11+0$ to $13+6$ weeks. Ultrasound Obstet Gynecol 2006;27:151-55.

169. Antolin E, Comas C, Torrents M, et al. The role of ductus venosus blood flow assessment in screening for chromosomal abnormalities at 10-16 weeks of gestation. Ultrasound Obstet Gynecol 2001;17:295-300. 
170. Kiserud T, Eik-Nes SH, Blaas HG, et al. Ductus venosus blood velocity and the umbilical circulation in the seriously growthretarded fetus. Ultrasound Obstet Gynecol 1994;4:109-14.

171. Hecher K, Campbell S, Doyle P, et al. Assessment of fetal compromise by Doppler ultrasound investigation of the fetal circulation: Arterial, intracardiac, and venous blood flow velocity studies. Circulation 1995;91:129-38.

172. Hecher K, Ville Y, Snijders R, et al. Doppler studies of the fetal circulation in twin-twin transfusion syndrome. Ultrasound Obstet Gynecol. 1995; 5:318-24.

173. Huisman TW, Bilardo CM. Transient increase in nuchal translucency thickness and reversed end-diastolic ductus venosus flow in a fetus with trisomy 18. Ultrasound Obstet Gynecol. 1997;10:397-99.

174. Montenegro N, Matias A, Areias JC, et al. Ductus venosus revisited: A Doppler blood flow evaluation in the first trimester of pregnancy. Ultrasound in Med and Biol. 1997;23:171-76.

175. Kisrud T. In a different vein: The ductus venosus could yield much valuable information. Ultrasound Obstet Gynecol 1997;9:369-72.

176. Borell A, Antolin E, Costa D, et al. Abnormal ductus venosus blood flow in trisomy 21 fetuses during early pregnancy. Am J Obstet Gynecol. 1999;179:1612-17.

177. Matias A, Gomes C, Flack N, et al. Screening for chromosomal abnormalities at 10-14 weeks: The role of ductus venosus blood flow. Ultrasound Obstet Gynecol 1998;12:380-84.

178. Matias A, Montenegro N, Areias JC, et al. Anomalous fetal venous return associated with major chormosomopathies in the late first trimester of pregnancy. Ultrasound Obstet Gynecol. 1998;11:209-13.

179. Matias A, Huggon I, Areias JC, et al. Cardiac defects in chromosomally normal fetuses with abnormal ductus venosus blood flow at 10-14 weeks. Ultrasound Obstet Gynecol 1999;14:307-10.

180. Matias A, Montenegro N, Areias JC, et al. Haemodynamic evaluation of the first trimester fetus with special emphasis on venous return. Hum Reprod Update. 2000;6:177-89.

181. Matias A, Ramalho C, Montenegro N. Search for hemodynamic compromise at 11-14 weeks in monochorionic twin pregnancy: Is abnormal flow in the ductus venosus predictive of twin-twin transfusion syndrome. J Matern Fetal Neonatal Med 2005;18: 79-86.

182. Braithwaite JM, Kadir RA, Pepera TA, et al. Nuchal translucency measurement: Training of potential examiners. Ultrasound Obstet Gynecol 1996;8:192-95.

183. Cicero S, Dezerega V, Andrade E, et al. Learning curve for sonographic examination of the fetal nasal bone at 11-14 weeks. Ultrasound Obstet Gynecol 2003;22:135-37.

184. Maiz N, Kagan KO, Milovanovic A, et al. Learning curve for Doppler assessment of ductus venosus flow at 11-13+6 weeks' gestation. Ultrasound Obstet Gynecol 2008;31:503-06.

185. Dagklis T, Plasencia W, Maiz N, et al. Choroid plexus cyst, intracranial echogenic focus, hyperechoic bowel and hydronephrosis in screening for trisomy 21 at $11+0$ to $13+6$ weeks. Ultrasound Obstet Gynecol. 2008;31:132-35.

186. Nicolaides KH, Snijders RJM, Gosden CM, et al. Ultrasonographically detectable markers of fetal chromosomal abnormalities. Lancet 1992;340:704-07.
187. Liao A, Sebire N, Geerts L, et al. Megacystis at 10-14 weeks of gestation: Chromosomal defects and outcome according to bladder length. Ultrasound Obstet Gynecol 2003;21:338-41.

188. Sebire NJ, Von Kaisenberg C, Rubio C, et al. Fetal megacystis at 10-14 weeks of gestation. Ultrasound Obstet Gynecol 1996;8:387-90.

189. Liao AW, Sebire NJ, Geerts L, et al. Megacystis at 10-14 weeks of gestation: Chromosomal defects and outcome according to bladder length. Ultrasound Obstet Gynecol 2003;21:338-41.

190. Ville Y, Lalondrelle C, Doumerc S, et al. First-trimester diagnosis of nuchal anomalies: Significance and fetal outcome. Ultrasound Obstet Gynecol 1992;2:314-16.

191. Brady AF, Pandya PP, Yuksel B, et al. Outcome of chromosomally normal live births with increased fetal nuchal translucency at 10-14 weeks' gestation. J Med Genet 1998;35:222-24.

192. Souka AP, Krampl E, Bakalis S, et al. Outcome of pregnancy in chromosomally normal fetuses with increased nuchal translucency in the first trimester. Ultrasound Obstet Gynecol 2001;18:9-17.

193. Mangione R, Guyon F, Taine L, et al. Pregnancy outcome and prognosis in fetuses with increased first-trimester nuchal translucency. Fetal Diagn Ther 2001;16:360-63.

194. Bilardo CM, Pajkrt E, de Graaf IM, et al. Outcome of fetuses with enlarged nuchal translucency and normal karyotype. Ultrasound Obstet Gynecol 1998;11:401-06.

195. Michailidis GD, Economides DL. Nuchal translucency measurement and pregnancy outcome in karyotypically normal fetuses. Ultrasound Obstet Gynecol 2001;17:102-05.

196. Shulman LP, Emerson DS, Grevengood C, et al. Clinical course and outcome of fetuses with isolated cystic nuchal lesions and normal karyotypes detected in the first trimester. Am J Obstet Gynecol 1994;171:1278-81.

197. Cheng C, Bahado-Singh RO, Chen S, et al. Pregnancy outcomes with increased nuchal translucency after routine Down syndrome screening. Int J Gynaecol Obstet 2004;84:5-9.

198. Senat MV, De Keersmaecker B, Audibert F, et al. Pregnancy outcome in fetuses with increased nuchal translucency and normal karyotype. Prenat Diagn 2002;22:345-49.

199. Cha'Ban FK, van Splunder P, Los FJ, et al. Fetal outcome in nuchal translucency with emphasis on normal fetal karyotype. Prenat Diagn 1996;16:537-41.

200. Michalaides GD, Econdomides DL. Nuchal translucency measurement and pregnancy outcome in karyotypically normal fetuses. Ultrasound Obstet Gynecol. 2001;17:102-05.

201. Souka AP, Krampl E, Bakalis S, et al. Outcome of pregnancy in chromosomally normal fetuses with increased nuchal translucency at 10-14 weeks of gestation. Ultrasound Obstet Gynecol. 2001;18:9-17.

202. Makrymidas G, Sotiradis A, Huggon IC, et al. Nuchal translucency and fetal cardiac defects: A pooled analysis of major fetal echocardiography centers. Am J Obstet Gynecol 2005;192:89-85.

203. Carvalho JS, Moscoso G, Ville Y. First trimester transabdominal fetal echocardiography. Lancet. 1998;351:1023-27.

204. Simpson JM, Jones A, Callaghan N, et al. Accuracy and limitations of transabdominal fetal echocardiography at 12-15 weeks of gestation in a population at high risk for congenital heart disease. Br J Obstet Gynaecol. 2000;16:30-36. 
205. Hyett JA, Clayton PT, Moscoso G, et al. Increased first trimester nuchal translucency as a prenatal manifestation of Smith-LemliOpitz syndrome. Am J Med Genet. 1995;58:374-76.

206. Nadel A, Bromley B, Benaceraff BR. Nuchal thickening or cystic hygromas in first- and second- trimester fetuses: Prognosis and outcome. Obstet Gynecol. 1993;82:43-48.

207. Brady AF, Pandya PP, Yuksel B, et al. Outcome of chromosomally normal livebirths with increased fetal nuchal translucency at 10-14 weeks' gestation. J Med Genet 1998; 35:222-24

208. Adekunle O, Gopee A, El-Sayed M, et al. Increased firsttrimester nuchal translucency: Pregnancy and infant outcomes after routine screening for Down's syndrome in an unselected antenatal population. Br J Radiol. 1999;72:457-60.

209. Maymon R, Jauniaux E, Cohen O, et al. Pregnancy outcome and infant follow-up of fetuses with abnormally increased first trimester nuchal translucency. Hum Reprod 2000;15:2023-27.

210. Hiippala A, Eronen M, Taipale P, et al. Fetal nuchal translucency and normal chromosomes: A long-term follow-up study. Ultrasound Obstet Gynecol. 2001;18:18-22.

211. Khong TY, De Wolf F, Robertson F, Brosens I. Inadequate maternal vascular response to placentation in pregnancies complicated by preeclampsia and by small-for-gestational age infants. Brit J Obstet Gynaecol. 1986;93:1049-59. 